Title:

\title{
2 Probing carbonate in bone forming minerals on the nanometre scale
}

3 Authors:

4 Michał M. Kłosowski ${ }^{1}$, Robert J. Friederichs ${ }^{2}$, Robert $\mathrm{Nichol}^{3}$, Nikolas Antolin ${ }^{3}$, Raffaella Carzaniga ${ }^{4}$, 5 Wolfgang Windl ${ }^{3}$,Serena M. Best ${ }^{2}$, Sandra J. Shefelbine ${ }^{5}$, David W. McComb ${ }^{3}$, Alexandra E. Porter ${ }^{1}$

$6 \quad{ }^{1}$ Department of Materials and Engineering, Imperial College London, London

$7 \quad{ }^{2}$ Department of Materials Science and Metallurgy, University of Cambridge, Cambridge

$8{ }^{3}$ Department of Materials Science and Engineering, The Ohio State University, Columbus

$9 \quad{ }^{4}$ London Research Institute, Cancer Research UK, London

$10{ }^{5}$ Department of Mechanical and Industrial Engineering, Northeastern University, Boston

12 Corresponding authors:

13 David W. McComb, Department of Materials Science and Engineering, The Ohio State University,

14 Columbus, OH 43210, USA; phone: +1-614-643-3462; e-mail: mccomb.29@osu.edu;

15 Alexandra E. Porter, Department of Materials and Engineering, Imperial College London, Royal

16 School of Mines, South Kensington Campus, London, SW7 2AZ, UK; phone: (+44)207594 9691; e-

17 mail: a.porter@imperial.ac.uk

18 Abstract:

To devise new strategies to treat bone disease in an ageing society, a more detailed characterisation of the process by which bone mineralizes is needed. In vitro studies have suggested that carbonated mineral might be a precursor for deposition of bone apatite. Increased carbonate content in bone may also have significant implications in altering the mechanical properties, for example in diseased bone. However, information about the chemistry and coordination environment of bone mineral, and their spatial distribution within healthy and diseased tissues, is lacking. Spatially resolved analytical transmission electron microscopy is the only method available to probe this information at the length scale of the collagen fibrils in bone. In this study, scanning transmission electron microscopy combined with electron energy-loss spectroscopy (STEM-EELS) was used to differentiate between calcium-containing biominerals (hydroxyapatite, carbonated hydroxyapatite, beta-tricalcium phosphate and calcite). A carbon K-edge peak at $290 \mathrm{eV}$ is a direct marker of the presence of carbonate. We found that the oxygen K-edge structure changed most significantly between minerals allowing discrimination between calcium phosphates and calcium carbonates. The presence of carbonate in carbonated HA (CHA) was confirmed by the formation of peak at $533 \mathrm{eV}$ in the oxygen K-edge. These observations were confirmed by simulations using density functional theory. Finally, we show that this method can be utilized to map carbonate from the crystallites in bone. We propose that our calibration library of EELS spectra could be extended to provide spatially resolved information about the coordination environment within bioceramic implants to stimulate the development of structural biomaterials. 


\section{Keywords:}

2 bioceramics, bone mineral, carbonate, STEM-EELS

3

4 
2 During evolution, organisms have developed various external and internal skeletal systems. The

3 skeleton performs a number of tasks: it provides a scaffold for the entire body; it is a vital component

4 of the movement apparatus; and it protects internal organs. Any scaffolding material needs to possess

5 particular properties, such as stiffness, strength and toughness. To achieve these characteristics soft,

6 but elastic protein is reinforced with stiff mineral in the mineralisation process. In living systems this

7 process typically occurs through a calcium based route. Mollusca and Arthropoda exoskeletons

8 incorporate mainly calcium carbonates, while Vertebrae endoskeletons adapt calcium phosphates as

9 building material [1,2].

10 For several decades hydroxyapatite $\mathrm{Ca}_{10}\left(\mathrm{PO}_{4}\right)_{6}(\mathrm{OH})_{2}$ has been used as the closest approximation of

11 the biomineral present in Vertebrae mineralised tissue [3-5]. Hydroxyapatites (HA) are the most

12 common phase present in natural systems; however, there are other forms of apatite that contain ionic

13 substitutions (e.g. carbonate, fluoride, sodium, potassium etc.). The composition of the mineral may

14 vary between tissues (e.g. bone, dentin, enamel, calcified tendon) [6], with age [7], as a function of

15 the mineralisation stage [8,9] and as a result of diseases such as osteogenesis imperfecta [10,11].

16 Modifications in apatite chemistry are present as substitutions into the lattice (e.g. carbonate or

17 silicate ion substitutions), and as different calcium phosphate phases (e.g. beta tricalcium phosphate

18 (bTCP) vs. HA) [8,12]. Compositional variations between, and within hard tissues, may control

19 mechanical properties such as the hardness or fracture toughness of each biomineral [13]. For

20 example, disruption to mineralisation processes may have significant implications in altering the

21 mechanical properties of tissues. In aged bone, carbonate replaces phosphate in the mineral lattice

22 contributing to bone brittleness [7].

23 Characterisation of minerals in tissues not only provides insight into disease states, but is also beneficial to synthetic bioceramics research, where biocompatibility, bioactivity (e.g. resorption or cardiovascular response), material properties and mineral nucleation are of paramount importance [14-17]. Apatites with various dopants (i.e. carbonate, silicon and fluoride), beta-tricalcium phosphate and various mixtures of them are among the most popular bone-like bioceramics made for medical applications [15-17]. These minerals are often used as a connective material between implant and bone or as a porous synthetic bone graft to reconstruct fractures; they are designed to encourage bioactive bone growth. Optimisation of the bioactivity of bioceramics requires precise control over their chemistry. Subtle changes in the chemical composition, e.g. as a result of the form of ionic substitutions, and phase purity leads to alteration in bioactivity [18-20]. Nano-scale modifications in the chemistry of these bioceramic implants have a direct impact on mechanical and chemical properties of the surrounding bone. For example, phase changes and changes in the local atomic order at grain boundaries of apatite crystals affects mineral dissolution and the ability of carbonate and silicate substituted HA to integrate with the surrounding collagen matrix [21,22]. Other surface changes may promote or demote creation of sacrificial layers, an important factor in mechanisms stopping fracture propagation [23]. In the future, the ability to analyse the coordination environment within these materials and probe substitution sites in the HA lattice will improve our understanding of mechanisms controlling their bioactivity which will open the door for synthesis of more bio-adaptive ceramics to replace diseased or fractured tissues.

42 One of the challenges in elucidating bioimineralisation processes is the ability to identify mineral

43 compositions at the nanometre scale, during tissue formation and disease. Acquisition of this 44 information is the first step in characterisation of different phases present in tissues and bioceramics. 
1 Since mineralisation events frequently occur at the length scale of the collagen fibrils [24], it is critical 2 that compositional information is acquired with nanometre scale spatial resolution.

3 X-ray absorption spectroscopy (XAS) is one of the most common methods used to characterise 4 biomineral chemistry at the nanometre scale. X-ray absorption near edge structure (XANES) has 5 provided a new insight into chemical environment of biominerals and mineralised tissues [25-

$630]$.While XAS studies provide a very high energy resolution, the spatial resolution is not adequate to 7 resolve features below $15 \mathrm{~nm}$ [31-33]. Although the average sized crystal platelets (100nm long, 50nm 8 wide, $5 \mathrm{~nm}$ thick $[34,35])$ could be examined, investigation of smaller $(5-10 \mathrm{~nm})$ features such as inter9 crystal spaces, grain boundaries and protein-mineral interfaces is below the spatial resolution limit of 10 XAS.

11

Scanning transmission electron microscopy (STEM) combined with electron energy-loss spectroscopy 13 (EELS) is the only technique capable of achieving nanometre scale resolved information about the 14 chemistry and coordination environment of minerals. Previous studies have attempted to identify 15 spectral fingerprints from bioceramics using STEM-EELS [36,37]. However, these studies did not consider carefully the effects of irradiation of biominerals, which makes the results liable to misinterpretation [38]. In addition, previous studies focused on selected edges, rather than comparing 18 edges of all characteristic elements present in the mineral (i.e. $\mathrm{P}, \mathrm{C}, \mathrm{Ca}, \mathrm{O}$ ). To our knowledge, no 19 previous studies have identified the presence of carbonate from bone mineral by studying fine 20 structure in the EELS spectra at these edges. Here we used EELS to discriminate between different bioceramic standards. Phase pure hydroxyapatite (HA), carbonated HA (CHA) and beta tricalcium phosphate (bTCP) were selected as these bioceramics are likely to be present in bone tissue at different stages of mineralisation $[8,9]$ or are relevant in clinically enhanced mineralisation. Calcium carbonates were examined to determine if carbonate ion substitution in the HA lattice is detectable with EELS. The near-edge core loss spectra of phosphate, carbon, calcium and oxygen were acquired and analysed for various forms of synthetic biomineral and also for healthy mouse bone tissue. A study of the effect of electron dose was conducted in order to observe changes in the spectra that result from electron beam-induced damage. 
2 A range of standards was investigated to represent the calcium-containing minerals suggested to be 3 present in calcified tissues [4,12] or bioceramics enhancing bone growth [21,22]. These minerals are 4 pure hydroxyapatite (HA), carbonated hydroxyapatite (CHA) with carbonate substituted for hydroxyl 5 and phosphate groups in various ratios (A vs. B type, respectively), beta-tricalcium phosphate (bTCP) 6 and calcite (CAL) (Table 1).

\subsection{Production of mineral standards}

8 Hydroxyapatite (HA) with a $\mathrm{Ca} / \mathrm{P}$ ratio of 1.67 was synthesised using a wet precipitation method 9 described by Akao and Jarcho that involves a reaction between $\mathrm{Ca}(\mathrm{OH})_{2}$ and $\mathrm{H}_{3} \mathrm{PO}_{4}$ where the $\mathrm{pH}$ is 10 kept above 10.5 using aqueous ammonia [39,40]. $\mathrm{CaCO}_{3}$ (Sigma Aldrich ACS reagent grade 239216) 11 was decarburised over night at $960{ }^{\circ} \mathrm{C}$ then cooled under vacuum. The resulting $\mathrm{CaO}$ was hydrated in 12 deionised water to form $\mathrm{Ca}(\mathrm{OH})_{2}$, then $\mathrm{H}_{3} \mathrm{PO}_{4} a q(85 \mathrm{v} / \mathrm{v} \%$ Fisher Scientific) was diluted in deionised 13 water and was added at a rate of $5 \mathrm{ml} \cdot \mathrm{min}^{-1}$ to the $\mathrm{Ca}(\mathrm{OH})_{2}$. Upon completion the mixture was aged overnight then vacuum filtered. The resulting filter cake was dried then ground in an alumina crucible.

A mixed $\mathrm{AB}$-type carbonated $\mathrm{HA}(\mathrm{CHA})$ was produced via a sodium free wet chemical precipitation reaction first described by Gibson \& Bonfield [41]. Ca/P ratios of 1.76, 1.74 and 1.72 were considered. Similarly to $\mathrm{HA}, \mathrm{Ca}(\mathrm{OH})_{2}$ was formed and $\mathrm{CO}_{2} g$ was bubbled through deionised water until the $\mathrm{pH}$ dropped to around 4 then $\mathrm{H}_{3} \mathrm{PO}_{4} a q(85 \mathrm{v} / \mathrm{v} \%$ Fisher Scientific) was added. This solution was added at a rate of $5 \mathrm{ml} . \mathrm{min}^{-1}$ to the $\mathrm{Ca}(\mathrm{OH})_{2}$ solution. No $\mathrm{pH}$ control was necessary as the $\mathrm{pH}$ remained above 10.5 .

A fraction of the apatite mineral standards were heat treated: at $1200{ }^{\circ} \mathrm{C}$ in air (HA) or $800-1000{ }^{\circ} \mathrm{C}$ in a wet $\mathrm{CO}_{2}$ environment (CHA) for 2 hours. The other fraction was investigated without heattreatment.

Beta-tricalcium phosphate (bTCP) precursors were formed through combination of $\mathrm{Ca}(\mathrm{OH})_{2}$ and $\mathrm{H}_{3} \mathrm{PO}_{4}$ in an aqueous environment with a $\mathrm{Ca} / \mathrm{P}$ ratio of 1.5 . This mixture was aged, dried and heated to $1100{ }^{\circ} \mathrm{C}$ for 4 hours to produce bTCP [42].

\subsection{Preparation of bone samples}

3 femurs of 8 week old wild type mice were prepared via high pressure freezing and freezesubstitution [43]. Bone samples were dissected, cut with a scalpel blade from the middle of each femur shaft, transferred into flat specimen carriers with $200 \mu \mathrm{m}$ indents and fixed with 1-hexadecene. Rapid cryofixation was done using a Leica EMPACT2 (Leica Microsystems, Vienna, Austria) machine. Frozen samples were transferred into a Leica EM AFS2 freeze-substitution device, where the substitution using acetone solution containing 3\% (v/v) glutaraldehyde was performed for $8 \mathrm{~h}$ at $90{ }^{\circ} \mathrm{C}$. The temperature was steadily increased $\left(5^{\circ} / \mathrm{h}\right)$, until it reached $0{ }^{\circ} \mathrm{C}$. Finally, samples were washed twice in acetone for $15 \mathrm{~min}$, before they reached room temperature.

For the first three days, samples were immersed successively in 1:3, 1:1 and 3:1 resin:acetone solutions for $24 \mathrm{~h}$. The resin was prepared from a mixture of $12.6 \mathrm{~g}$ of Quetol651, $15.5 \mathrm{~g}$ of nonenylsuccinic anhydride (NSA), $6.5 \mathrm{~g}$ of methylnadic anhydride (MNA) and $0.6 \mathrm{~g}$ of benzyldimethylamine (BDMA), (Agar Scientific, Dorset, UK). Finally, samples were placed in pure

40 embedding resin for 7 days allowing full infiltration under vacuum. The resin was changed daily.
41 After eight days, the samples were moved into the curing oven and heated at $60^{\circ} \mathrm{C}$ for $48 \mathrm{~h}$. An 
1 ultramicrotome PowerTome XL with an ultra $45^{\circ}$ diamond blade (Diatome, Biel, Switzerland) was 2 used to prepare ultra-thin $(70 \mathrm{~nm})$ sections of embedded samples. 
2 The phase purity of heat-treated powders was investigated with X-ray diffraction (XRD). Powder

3 XRD scans were performed using a Phillips PW1050 diffractometer with monochromatic Cu K- $\alpha$ X-

4 rays operating at $40 \mathrm{kV}$ and $40 \mathrm{~mA}$. $0.5^{\circ}$ divergence and anti-scatter slits, a $10 \mathrm{~mm}$ mask and a 0.2

5 mm-receiving slit were used. Scans used a $0.05^{\circ}$ step size and a sweep rate of $1^{\circ} 2 \theta / \mathrm{min}$. Phillips

6 HighScore plus software was used to identify phases in the heat-treated CaP powders. ICDD

7 (International Centre for Diffraction Data) powder diffraction files of HA (09-0432), alpha-tricalcium

8 phosphate (29-0359), beta-tricalcium phosphate (bTCP, 70-2065), calcium oxide (37-1497), tetra

9 calcium phosphate (TTCP, 25-1137), calcite (CAL, 85-1108) and aragonite (41-1475) were considered

10 during phase analysis.

11 Carbonate groups in hydroxyapatites can occupy two possible positions; hydroxyl (A-type) or 12 phosphate (B-type) group substitutions [44,45]. Several variants of CHA were produced, in order to 13 obtain a high and low $\mathrm{A} / \mathrm{B}$ type carbonate ratio, to reflect clinical findings that $\mathrm{A} / \mathrm{B}$ ratio varies in 14 bone between species [45].

15 To determine the substitution sites of carbonate ion in the HA lattice, apatites were examined using 16 Fourier transform infrared spectroscopy (FTIR, Perkin Elmer Spectrum 100 spectrometer), and the $17 \mathrm{~A} / \mathrm{B}$ ratio was estimated as the ratio of areas of peaks corresponding to A and B substitutions [46].

18 To obtain a spectrum, 32 scans were performed with a resolution of $1 \mathrm{~cm}^{-1}$. The FTIR spectra were 19 cropped to the region of interest showing carbonate peaks $\left(840-900 \mathrm{~cm}^{-1}\right)$. Spectra were deconvoluted 20 using the Peak Analyzer tool in Origin (OriginLab, Northampton, MA, USA). After subtraction of a 21 linear, integrated background, three Gaussian peaks were fitted corresponding to A $\left(\sim 880 \mathrm{~cm}^{-1}\right), \mathrm{B}$ $22\left(\sim 873 \mathrm{~cm}^{-1}\right)$ and $\mathrm{C}\left(\sim 867 \mathrm{~cm}^{-1}\right)$ type substitutions (Figure SI 1). Integrated intensities of respective, 23 deconvoluted peaks were used to establish the A/B ratio. 
2 For STEM-EELS investigations, the mineral powders were dispersed in $100 \%$ ethanol and then

3 transferred onto copper 300-mesh grids coated with a lacy carbon film as a support (Agar Scientific

4 Ltd., Dorset, UK).

5 The specimens were examined on the FEI Titan 80-300 field emission, Cs corrected electron

6 microscope fitted with a Gatan Tridiem electron energy-loss spectrometer. The instrument was

7 operated at an accelerating voltage of $300 \mathrm{kV}$ and an emission voltage of $4500 \mathrm{~V}$, conditions

8 frequently used to study mineralised tissues to minimise radiolysis damage [12,47]. For EELS

9 analysis, the microscope was aligned in STEM mode with a $50 \mu \mathrm{m}$ condenser aperture, spot size 9, a

10 camera length of $60 \mathrm{~mm}$ and a spectrometer entrance aperture of $2.5 \mathrm{~mm}$, corresponding to

11 convergence and collection semi-angles of 8 and $14 \mathrm{mrad}$, respectively. The core loss signal was

12 acquired in 10 second acquisitions with sub-pixel scanning. Beam parameters were optimised to

13 ensure the total electron dose for the specimen would not exceed $10^{4}$ electrons $/ \mathrm{nm}^{2}$, which is below

14 threshold dose for damage of these minerals [38]. Each spectrum was collected with energy

15 resolution of $0.6-0.7 \mathrm{eV}$ using an energy dispersion of $0.05 \mathrm{eV} / \mathrm{channel}$.

16 For the damage study, doses higher than $10^{4}$ electrons $/ \mathrm{nm}^{2}$ were also tested. Samples were exposed to

17 dose rates of $10^{3}$ electrons $/ \mathrm{nm}^{2}$ per second. The signal was acquired in 1 second increments for 120

18 seconds.

19 A background subtraction was performed on all acquired edges. The background signal was removed

20 by subtraction of a power-law fit to a $25 \mathrm{eV}$-wide window ( $10 \mathrm{eV}$ for the phosphorus edge) preceding

21 the edge of interest. The window position was selected to ensure that background-subtracted spectrum does not become unphysical i.e. intersects the energy-loss axis. Examples of background subtraction are shown in Figure SI 3 \& Figure SI 4. The background subtraction was performed using Digital Micrograph software (Gatan, Pleasanton, CA, USA). All EELS figures show spectra after background subtraction. Resulting spectra were normalised and calibrated to the characteristic peaks (for details of calibration see the results section).

For the examination of possible impurities in the calcite sample, where overlapping structures of carbon film and mineral were observed in the carbon K-edge, a principal components analysis (PCA) approach was applied to separate superpositioned spectra [48]. In PCA, the original spectra are decomposed into a set of orthogonal spectra. These spectra are weighted according to their contribution to the original spectrum, while spectra not showing any meaningful features can be discarded as noise. Finally the data set may be reconstructed from spectra carrying valuable information. For this processing Hyperspy open source software was used [49]. The spectra collected from a cluster of unidentified mineral on a carbon film (Figure SI 4) were decomposed using Hyperspy software. The decomposition procedure used the singular value decomposition algorithm and assumed a Gaussian distribution of noise. The resulting scree plot, scores and loading of first nine components are given in Figure SI 5.The decomposition was followed by the independent component analysis (ICA), which aims to identify the real (or at least more physically meaningful) components of the multiple original signals mixture. Finding the real components depends on the selection of "contrast functions". Contrast functions indicate the degree of componential independence, and the most independent components are considered as the original signals. The ICA procedure (via the 42 FastICA algorithm [50]) was used in the attempt to reconstruct independent components of the 43 overlapping materials. 
1 To aid the interpretation of the oxygen K-edge data, the energy-loss near-edge structure (ELNES) was 2 simulated using density functional theory. The site projected unoccupied density of states (DOS) on 3 the oxygen atomic sites was calculated using VASP 5.3.5 with PAW-PBE pseudo-potentials and a $42 \times 2 \times 3$ supercell [51-58] To evaluate whether core-hole effects are reflected in spectra, a Z+1 5 approximation was utilized to simulate an excited-state system[59]. The resulting density of states 6 was convoluted with a Gaussian function to simulate the product of experimental, final state, and 7 initial state broadening. The energy dependence of final state broadening was not considered as this 8 would have a minor effect on the simulation of the ELNES in the energy range of interest here. 


\subsection{Bulk characterisation}

4

CHA standards with the highest and lowest $\mathrm{A} / \mathrm{B}$ ratio were selected for subsequent characterisation to represent the extremes of carbonate substitutions (Figure 1, Table 1, Table 2).

XRD revealed that all mineral standards were phase pure (Figure 1). The only phase present in heat treated HA and CHA was hexagonal HA (ICDD 09-432). bTCP (ICDD 70-2065) did not contain any $\alpha$-TCP or HA impurities. The as-received $\mathrm{CaCO}_{3}$ from Sigma Aldrich was a pure calcite phase (ICDD 85-1108). One should keep in mind that the estimate of the purity at the macroscale might give an error of $2-6 \%$ [47]. This inaccuracy in the estimation may lead to observations of various phases at the nanometre scale.

\subsection{EELS characterisation}

No meaningful differences in EELS spectral features were observed between non-sintered hydroxyapatite and hydroxyapatite sintered in $1200^{\circ} \mathrm{C}$ (data not shown). No meaningful differences in EELS spectral features were observed between various carbonated hydroxyapatites (type A or B substitution) (data not shown). Representative hydroxyapatite spectra were labelled as HA, and representative carbonated apatite spectra were labelled as CHA.

\subsubsection{Phosphorus $\mathrm{L}_{2,3}$-edge}

EELS data from the phosphorus-containing minerals are shown in Figure 2. The phosphorus $\mathrm{L}_{2,3}$-edge displays three main peaks in the energy loss near-edge structure (ELNES): peaks A, B and C at $\sim 138$, $\sim 141$ and $146-149 \mathrm{eV}$, respectively. These features precede a broad peak D at $\sim 160 \mathrm{eV}$. Phosphorus $\mathrm{L}_{2,3}$-edge spectra were normalised and aligned to the first peak A set to $138 \mathrm{eV}$ based on the literature [60]. Background subtraction of the phosphorus $\mathrm{L}_{2,3}$-edge was performed using a pre-edge, $10 \mathrm{eV}$ window.

Peak A can be assigned to transitions from the phosphorus $2 \mathrm{p}$ core states to unoccupied states of $\mathrm{p}$-like symmetry [60]. Monopole transitions (p-to-p state) are not allowed by the dipole selection rule.

However, if a hybrid $\mathrm{sp}^{3}$ (combination of $3 \mathrm{~s}$ and $3 \mathrm{p}$ state) state is formed, the dipole selection rule can be satisfied by transitions to the s-like component of this state [61]. Additional mixing with hybrid $\mathrm{sd}^{3}$ states may further increase the probability of this transition occurring [61,62]. By analogy, peak B has been attributed to transitions from $2 \mathrm{p}$ state to $\mathrm{p}$-like final states. Kruse et al. suggested that peak B arises due to mixing of phosphorus p-states and calcium d-states [60]. Peak $\mathrm{C}$ was formed by electrons excited to d-like states $[60,63]$. Peak D with a maximum at $\sim 160 \mathrm{eV}$ is attributed to a cross section maximum of $2 p$ state excitations [63] and multiple scattering. There was no observable difference in the phosphorus $\mathrm{L}_{2,3}$-edge from phosphorus-containing minerals shown in Figure 2. 
2 The carbon K-edge spectra of carbonated minerals were normalised and aligned to the carbonate peak

3 D (Figure 3) set to standard $290 \mathrm{eV}$, based on the literature [27]. The amorphous carbon spectrum

4 (AC) of the carbon film was collected during the same acquisition as the calcium carbonate spectra.

5 The AC spectrum was normalised to peak A of CHA.

6 The spectrum from calcite, $\mathrm{CaCO}_{3}(\mathrm{CAL}$, Figure 3) was consistent with the literature [64] and

7 exhibits a distinct, sharp peak D at $\sim 290 \mathrm{eV}$, less intense peaks $\mathrm{E}$ and $\mathrm{G}$ at $\sim 296$ and $\sim 298 \mathrm{eV}$,

8 respectively, and a broader peak $\mathrm{H}$ at $\sim 302 \mathrm{eV}$.

9 The CAL standard was nominally a 99\% pure phase calcite. Impurities detected during in the EELS

10 study exhibited spectra with characteristics similar to aragonite. In addition to aragonite-like features,

11 these spectra showed additional peaks typical for organic compounds $[65,66]$. Impurity particles were

12 found exclusively on the support film. Therefore spectra acquired from impurities represent a

13 superposition of amorphous carbon film and unknown phase spectra, and were analysed using ICA.

14 In Figure 3, IMP is the spectrum obtained via the ICA blind source separation method [48], which

15 extracts a full spectral signal of each individual phase present in the examined region. Original spectra

16 and extracted spectra are presented on Figure 4. We repeated the ICA to reconstruct up to 6

17 independent components. However, the combination of just first two components gave a good

18 approximation of the initial spectrum (Figure SI 6III); hence we assume that the original signal is a

19 mixture of two signals. After application of ICA, the first spectrum obtained exhibited features

20 consistent with an amorphous carbon film, while the second spectrum represented the unknown

21 mineral impurity.

22 The impurity spectrum (IMP), in comparison to calcite (CAL), displayed additional double peaks B 23 and C at $\sim 287$ and $\sim 288 \mathrm{eV}$, respectively. Peaks E and G, seen in calcite, are barely visible in the 24 impurity spectrum and peak $\mathrm{H}$ is shifted towards lower energies.

25 Peaks B and C observed in the calcite impurity (IMP) were assigned to $1 \mathrm{~s} \rightarrow \pi^{*}$ states transitions of 26 carboxyl and carbonyl groups, which are often connected with organic material in aragonite in 27 XANES studies [67-69]. Previous EELS studies did not record peaks B and C in aragonite [64], while 28 XANES studies show the presence of peaks B and C, and attributed their origin to the surface 29 contamination or surface states [70].

The most distinct peak in calcium carbonates (D at $\sim 290 \mathrm{eV}$ ) originates from main core 1s transitions to the vacant $\pi^{*}$-A states of $\mathrm{CO}_{3}$ groups [27]. Peaks $\mathrm{E}$ (CAL, IMP) and G (CAL) were assigned to carbonate $1 \mathrm{~s} \rightarrow \sigma^{*}-\mathrm{C}$ and $\pi^{*}-\mathrm{C}$ transitions $[28,70]$. Peak $\mathrm{H}$ results from the main $1 \mathrm{~s} \rightarrow \sigma^{*}$-A transitions [70,28].

Carbonated HA (CHA) exhibited four peaks: A at $\sim 285 \mathrm{eV}, \mathrm{D}$ at $\sim 290 \mathrm{eV}, \mathrm{F}$ at $\sim 297 \mathrm{eV}$ and $\mathrm{H}$ at $\sim 302$ $\mathrm{eV}$. Low signal-to-noise ratio of CHA carbon K-edge is the effect of relatively low carbonate content and the low dose exposure. Pure calcium phosphates (HA and bTCP) exhibit no carbon signal or a weak signal corresponding to amorphous carbon, which could be attributed to impurities introduced during preparation of standards or accumulation of mobile hydrocarbons originating from carbon 40 support film (data not shown). The amorphous carbon edge consists of two peaks a sharper one A at $41285 \mathrm{eV}$ characteristic for core electron transitions from $1 \mathrm{~s}$ to vacant $\pi^{*}$ state and a broad peak $\mathrm{F}$ at $42 \sim 297 \mathrm{eV}$ characteristic for $1 \mathrm{~s} \rightarrow \sigma^{*}$ transitions in the carbon-carbon bonding environment [71]. 
1 Peak D is characteristic of the presence of carbonate ions (Figure 3) [66]. Analysis of the carbon K2 edge alone is not sufficient to distinguish between $\mathrm{CaCO}_{3}$ and $\mathrm{CHA}$ [25], as the CHA spectra hold 3 strong resemblance to edges collected from calcite and aragonite and may be approximated as a 4 superposition of features visible for amorphous carbon and calcite. 
2 Calcium $\mathrm{L}_{2,3}$-edge spectra were aligned and normalised to the peak $\mathrm{B}$, set to $348 \mathrm{eV}$ based on

3 literature [30]. The calcium $\mathrm{L}_{2,3}$ ELNES (Figure 5) consists of two principal sharp peaks: B at $\sim 348$

$4 \mathrm{eV}$ and $\mathrm{D}$ at $\sim 350 \mathrm{eV}$, corresponding the spin-orbit split $\mathrm{L}_{3}$ and $\mathrm{L}_{2}$ edges, respectively $[72,73]$.

5 In the calcite spectrum each of the principal peaks (B, D) was split, creating additional, smaller peaks

6 (A, C) at $\sim 346$ and $\sim 350 \mathrm{eV}$, as a result of the crystal field splitting [28,70-72]. We did not observe

7 these features in other minerals, possibly due to insufficient energy resolution. Nevertheless, some

8 carbonated hydroxyapatite species showed a slight broadening of the FWHM (around $0.3 \mathrm{eV}$ ), which

9 may indicate the multiplet splitting [29,74].

10 The features characteristic of multipet splitting were observed in the calcium $\mathrm{L}_{2,3}$-edge of calcite

11 spectrum due to the highly symmetric calcium coordination environment. In calcite, the calcium atom

12 is in octahedral configuration with six oxygens; in aragonite, calcium is positioned in irregular

13 environment of nine oxygens; in apatites, calcium atoms occupy two positions: one in coordination

14 with nine oxygen atoms (Ca1), other with seven (Ca2) [29]. In the impurity found in calcite and HA

15 and CHA, the d orbitals undergo a complex crystal field splitting resulting in multiple peaks that are

16 unresolved. In comparison, XANES experiments showed calcite-like crystal field splitting for

17 carbonated hydroxyapatites, aragonite [29] and even hydroxyapatite [75].

18 Most examined minerals (HA, CHA, bTCP, IMP) did not exhibit meaningful modifications in the 19 calcium $\mathrm{L}_{2,3}$-edge. Only calcite displayed distinctive features (A, C), which are characteristic of 20 multiplet splitting. 
3 Changes were observed in the oxygen K-edge structure, which are connected with two different

4 damage processes. In the first process, minerals exposed to electron doses above $10^{4}$ electrons per $\mathrm{nm}^{2}$

5 exhibited a characteristic peak $\mathrm{X}$ at $\sim 530 \mathrm{eV}$. In the second process, minerals exposed to doses above

$610^{5}$ electrons per $\mathrm{nm}^{2}$ showed the transformation of the oxygen K-edge structure into spectra

7 consistent with calcium oxide features. These observations are presented first as the damage peak $\mathrm{X}$

8 was used to align oxygen spectra.

9 We also observed electron radiation induced damage in the HA and CHA oxygen K-edge for samples 10 exposed to higher doses (above $10^{5}$ electrons per $\mathrm{nm}^{2}$ ). During the exposition, formation of peaks B* 11 and $\mathrm{E}^{*}(\mathrm{HA}$ into $\mathrm{CaO}$, Figure 6$)$ and a decrease in the intensity of peak $\mathrm{C}$ were observed (HA

12 damaged, Figure 6). The final structure of oxygen $\mathrm{K}$-edge transformation (HA into $\mathrm{CaO}$, Figure 6) is 13 consistent with the pattern attributed to calcium oxide found in the literature [76].

14 For doses exceeding $10^{4}$ electrons per $\mathrm{nm}^{2}$ [38], many minerals exhibit a strong peak X at $530 \mathrm{eV}$ (HA 15 damaged, CAL damaged, Figure 6). Peak $\mathrm{X}$ is a sign of damage induced by formation of $\mathrm{O}_{2}$ oxygen 16 molecules [77] or other forms of oxygen radicals, like $\mathrm{OH}$ or $\mathrm{CO}$, and is a good marker of early 17 damage modifications of the sample's chemistry. Some studies interpreted the X peak damage signal 18 as the hydroxyl group or a water presence marker [36,37]. Garvie questioned this approach and 19 showed that a direct relation between hydroxyl or water presence and a damage signal cannot be 20 derived [38]. After prolonged exposure to the beam radiation, HA transforms into calcium oxide [78]. 21 It was previously reported, that this transformation occurs in apatites exposed to an electron dose exceeding $10^{8}$ electrons per $\mathrm{nm}^{2}$ [79]. However, we observed HA-to-CaO transformation at a much lower dose.

As biominerals are prone to degrade under specific beam conditions, precautions need to be taken to preserve their structural and chemical integrity. However, these changes are frequently not considered in the literature, which makes data liable to misinterpretation [38]. Prolonged beam exposure leads to modifications, such as breakdown of elemental bonds, formation and reconstruction of voids and transformations into other compounds [80].

The oxygen coordination environment is sensitive to beam-induced modifications, which makes it an excellent marker for the low dose damage. A total dose of $10^{4}$ electrons per $\mathrm{nm}^{2}$ is sufficiently low to avoid the radiation damage observed in biominerals. Nevertheless, we recommend monitoring the oxygen edge to minimise the possibility of damage.

\subsubsection{Oxygen}

Oxygen spectra were aligned using the damage peak $\mathrm{X}$ set to $530 \mathrm{eV}$ based on the literature [38].

36 First, the undamaged signal was acquired, and then acquisition was continued until a peak at $530 \mathrm{eV}$ started to form. Spectra were normalised to the most intense peak of each individual spectrum.

All phosphorus-containing minerals examined (HA, CHA, bTCP, Figure 7) exhibited a characteristic double peak C-D at $\sim 537$ and $\sim 539 \mathrm{eV}$, respectively. On the high energy shoulder of peak D, a small peak $\mathrm{F}$ is positioned at $\sim 545 \mathrm{eV}$. Carbonated HA exhibited an additional, low-energy shoulder B at $\sim 533 \mathrm{eV}$. 
1 Calcium carbonates (CAL \& IMP) exhibited a pronounced peak B at $\sim 533 \mathrm{eV}$ followed by smaller peaks $\mathrm{C}, \mathrm{E}$ and $\mathrm{F}$ at $\sim 537, \sim 540$ and $\sim 545 \mathrm{eV}$. Although the calcite and calcite impurity show a similar distribution of peaks, the intensity of particular peaks fluctuates. Namely, the intensity of peak B is relatively lower in IMP, while $\mathrm{E}$ is the highest in IMP. The impurity spectrum also displays shoulder A at $\sim 531 \mathrm{eV}$. The oxygen K-edge of IMP is consistent with aragonite spectra in the literature [64].

6 Literature on the oxygen K-edge configuration in calcium-containing minerals is limited. Transitions 7 of core 1s electrons to molecular vacant $\pi^{*}$ states of carbonate are responsible for the formation of 8 peak B, while $1 \mathrm{~s}$ transitions to vacant $\sigma^{*}$ states result in formation of E peak at approximately $540 \mathrm{eV}$ 9 [81].

10 EELS and XANES studies on metal oxides suggests peaks $C$ and $D$ to originate from transitions to 11 hybrid $3 \mathrm{~d}$ calcium/2p oxygen orbitals ( $\pi^{*}$ and $\sigma^{*}$, respectively) [82,83]. Similarly, peak E and F would represent transitions to higher energy hybrid states $4 \mathrm{~s}-$ and $4 p-l i k e[82,83]$. In oxides, separation of peaks $\mathrm{C}, \mathrm{D}, \mathrm{E}$ and $\mathrm{F}$ should be consistent with peak separation seen in metal $\mathrm{L}_{2,3}$-edges (calcium peaks A-D). However, such consistency was not observed in the minerals examined here, 15 which suggests a more complex hybridisation of oxygen orbitals. For example, formation of peak D 16 may be also attributed to hybrid phosphorus-oxygen orbital transitions, as this peak is observed only 17 in phosphorus-containing minerals.

18 Previously, Gregori et al. [84] proposed that the presence of peak $\mathrm{C}$ is characteristic of HA, while a 19 decrease in the intensity of peak C indicate presence of bTCP. We detected presence of both peaks in 20 HA, CHA and bTCP. No meaningful variation in the C/D intensity ratio was observed.

In CHA, the C-D double peak is preceded by a broad shoulder B at $\sim 533 \mathrm{eV}$ (Figure 7). This shoulder corresponds to calcium carbonates (CAL, IMP) initial shoulder and peak. Shoulder B observed in CHA has a low intensity, which might be attributed to relatively low amount of carbonate present in the crystal lattice.

The oxygen K-edge structure changes most significantly between minerals allowing discrimination of examined ceramics. The oxygen signal can distinguish between calcium phosphates and calcium carbonates. The presence of carbonate in carbonated HA (CHA) is confirmed by formation of peak B at $533 \mathrm{eV}$ (Figure 7).

The ability to identify the presence of carbonate ions with good spatial resolution would be an important analytical tool for the study of wide range of problems in biomineralisation research. In order to confirm the interpretation of the experimental data, we attempted to simulate the oxygen Kedge ELNES for both HA and CHA.

Oxygen K-ELNES for HA was simulated using experimental structure parameters obtained from xray diffraction studies [85]. Since partial occupancy is not possible in explicitly atomistic simulations, a random structure program was utilized to populate two of the four possible hydroxide positions to remove investigator bias [86]. Besides the ground-state site-projected electronic DOS, we have utilized the $\mathrm{Z}+1$ approximation to simulate an excited-state that includes a core-hole $[59,87]$. Comparison of the site projected DOS of the ground state and excited state $Z+1$, calculations with the experimental oxygen K-ELNES (Figure 8) shows that the effect of the core-hole is to move intensity towards the edge onset. A linear combination of the ground state and excited state models gives an excellent agreement with the experimental data, suggesting partial screening of the core hole. 
1 For carbonated hydroxyapatite a relaxed structure was used in which both, an A site and a B site, 2 carbonate substitution is present in the primitive cell [88]. The objective was to establish if the 3 carbonate bonded oxygen atoms contribute additional low energy intensity to the oxygen K-edge seen 4 in the experimental spectra (Figure 7). In the CHA, only the projected DOS was calculated, as there 5 are twenty-seven unique oxygen atoms that would each need to be treated independently to construct 6 a Z+1 model. The contributions from all oxygen atoms to the unoccupied p-like states were compared 7 with the contributions from those of non-carbonated oxygen atoms (Figure 9), which showed that 8 carbonate oxygen atoms increase the relative intensity of the lowest-energy peak. Finally a model in 9 which the carbonate groups in CHA were replaced with phosphate and hydroxyl groups with $\mathrm{AB}$ 10 substitution was also considered. The results in Figure 9 show clearly that introduction of carbonate 11 ions results in a small pre-peak on the oxygen K-ELNES which is consistent with the experimental 12 data. 
2 Changes in fine features of elemental edges observed in bioceramic standards will help to interpret

3 fine structure seen in the EELS spectra taken from bone mineral (Figure 10) and other mineralising 4 tissues.

5 To demonstrate that STEM-EELS has the spatial resolution to map the distribution of compositional 6 variations within ceramics, we have acquired spatially resolved chemical maps and shown, that there 7 are small $(>20 \mathrm{~nm})$ clusters within the bulk of the CHA with a higher concentration of carbonate than 8 is present in the surrounding material (Figure SI 7).

9 To validate this approach for biomaterials, we performed EELS of bone taken from a murine model. 10 Bone mineral possesses the major characteristic features of carbonated apatite. In the phosphorus L11 edges (Figure $10 \mathrm{I}$ ), peaks $\mathrm{A}$ and $\mathrm{C}$, assigned to transitions from the $2 \mathrm{p}$ core states to unoccupied states 12 of p-like and d-like symmetry, were observed. In the carbon K-edges (Figure 10 II), peaks A and D, 13 assigned to $1 \mathrm{~s}$ - transitions in $\mathrm{C}=\mathrm{C}$ bonds and in carbonate, respectively, were detected. In the calcium 14 L-edges (Figure $10 \mathrm{III}$ ), peaks B and D assigned to spin-orbit splitting, were measured. In oxygen K15 edges (Figure $10 \mathrm{IV}$ ), peaks $\mathrm{C}$ and $\mathrm{D}$ were observed, which were attributed to various transitions to $\mathrm{p}$ 16 like states of all oxygen atoms. Spatially resolved maps at the carbon K-edge showed variation in the 17 fine structure between intra- and extra-fibrillar regions of bone (Figure SI 8 \& SI 9). The intrafibrillar 18 regions usually exhibited a peak at $290 \mathrm{eV}$ corresponding to the presence of carbonate.

19 Examination of carbon K-edge successfully revealed the presence of carbonate in bone (peak D), 20 confirming that it is possible to detect carbonate in bone with the nanometre scale spatial resolution 21 using EELS. 
2 The chemical composition of biologically formed minerals at the nanometre scale is complex and employment of standards is essential to unravel the exact composition of biological systems. In particular, to establish whether the carbonate signal originates from calcium carbonate, carbonated HA or other minerals. We have successfully shown that EELS can be used to detect the presence of carbonate in bone mineral and can be utilised to differentiate between calcium carbonates, carbonated HA and pure HA in hard tissues and synthetic bioceramics, by comparing the carbon and oxygen Kedges. We also discovered a nanometre scale impurities and inhomogeneities in prepared mineral standards. Observation of EELS spectra did not reveal any features that might indicate carbonate substitution site in carbonated apatite (CHA), but carbonate substitution site location and orientation has been previously shown using other techniques such as FTIR [41] and neutron powder diffraction [88].

13 Discrimination between calcium phosphates (HA, CHA, bTCP) and calcium carbonates (CAL, IMP) can be performed directly via observation of the oxygen K-edge (Figure 5). The oxygen edge also provides sufficient information to discriminate between carbonate polymorphs: calcite and aragonitelike impurities. EELS was also capable of detecting small amounts of carbonate present in HA by observation of fine features in the carbon and oxygen K-edges. However, we were not able to 18 distinguish between HA and bTCP.

19 At the oxygen K-edge, calcium phosphates exhibited the presence of a characteristic double peak at $20 \sim 537$ and $\sim 539 \mathrm{eV}$ and the absence of a strong peak at $\sim 533 \mathrm{eV}$, which is characteristic of calcium carbonates. Calcium carbonate polymorphs (calcite and aragonite) might be discriminated between by the presence (CAL) or absence (IMP) of the peak at $\sim 537 \mathrm{eV}$. The presence of carbonated HA can be confirmed by mutual observation of the peak at $\sim 290 \mathrm{eV}$ in the carbon K-edge and the double peak at $\sim 537$ and $\sim 539 \mathrm{eV}$ in the oxygen $\mathrm{K}$-edge. CHA also displayed a shoulder at $\sim 533 \mathrm{eV}$ in the oxygen edge. This interpretation was supported by calculations of the oxygen K-ELNES.

In contrast, the phosphorus and calcium $\mathrm{L}_{2,3}$-edges displayed only subtle changes between bioceramics, such as peak shifts. Changes in the separation of peaks might originate from alterations in the bonding environment caused by the differences in crystal structures and/or the presence of dopants (Figure 1, Figure 4). Employment of monochromated EELS, which provides a better energy resolution $(<0.5 \mathrm{eV})$, would be beneficial for further examination of elemental edges. Especially observation of small magnitude shifts, which may be easily obscured by experimental noise, in phosphorus and calcium edges would provide additional information, which would be helpful in discrimination of bioceramics.

34 The main limiting factor in analytical studies of biominerals is their relative susceptibility to beam damage, like oxygen ionisation. Some studies neglected the importance of damage [38]; studies, which do consider damage, do not report the acquisition conditions in a reproducible manner [89]. Here, we described the most characteristic damage markers observed in the oxygen K-edges and their threshold conditions. Selection of appropriate experimental conditions is crucial to reduction of possible damage, while maintaining a high signal-to-noise ratio at the same time to distinguish between different species. Data collected without appreciation of damage mechanisms will be liable to misinterpretation about the native mineral composition and structure.

42 Studies of bone and other mineralizing tissues may provide additional challenges. One of the concerns 43 is the effect of sample preparation for electron microscopy. Previous studies using both 
1 ultramicrotomy and focus ion beam milling for the preparation of tissues shown that there is no

2 change in chemical signatures, which might arise from the fixative and resin [12,90]. Another

3 challenge arises due to the intrinsic heterogeneity of tissues. The emphasis needs to be put on the

4 examination of characteristic nanofeatures, such as collagen gap and overlap regions.

5 In summary, STEM-EELS was successfully used to differentiate between calcium-containing

6 biominerals (hydroxyapatite, carbonated hydroxyapatite, beta-tricalcium phosphate and calcite) and

7 we show that this method can be utilized to map carbonate from the crystallites in bone. We also

8 show that EEL spectrum images can be used to map small variations in carbonate distribution within

9 CHA with a spatial resolution of $5 \mathrm{~nm}$.

10 In mineralising tissues, the nanometre scale resolution is necessary to distinguish between

11 extrafibrillar and intrafibrillar mineral distributed in gap and overlap regions of a collagen fibril and to

12 observe initial nucleation clusters. This technique would be also beneficial for studying biocreamics

13 chemistry across grains, grain boundaries and other nanometre scale features. It is important that these

14 materials are phase pure to ensure that we have full control over their bioactivity.

15 EELS is currently the only technique capable of providing spatially resolved maps of the chemistry

16 and coordination environment of bioceramics and mineralizing tissues with nanometre (potentially

17 sub-nanometre) resolution. Synchrotron XRD [91,92] and nanoFTIR [93] can be used to map

18 minerals with the micron and sub-100 nm resolution, respectively, and provide important

19 complementary information to STEM-EELS about the chemical composition within bioceramics and

20 bone. Applied in combination with EELS these methods will open the door for possibilities to develop more detailed mineralisation models and will enable nano-scale characterisation of the distribution of substituted ions in bioceramics and of tissue/implant interfaces ex vivo. The combination of bulk techniques (in which average composition is assessed) and spatially resolved techniques, such as EELS, allows for composition to be assessed and compared at multiple length scales. High resolution techniques are particularly critical for understanding biological processes that occur on the nanometre length scale, such as mineralization or the mineral-collagen interface.

This research was funded by the UK Engineering and Physical Sciences Research Council. MMK acknowledges Armourers \& Brasiers' Gauntlet Trust. RJF acknowledges support from a National Science Foundation Graduate Research Fellowship (DGE-1042796) and a Cambridge International Scholarship from the Cambridge Overseas Trusts. NA acknowledges funding from a DOE-NEUP Fellowship under Award \# DE-NE0000110. DWM acknowledges support from the Ohio Third Frontier program though the Ohio Research Scholar award. AEP acknowledges an ERC individual starting investigator grant (CNTBBB) and an Elsie Widdowson research fellowship from Imperial College London. This work was supported in part by an allocation of computing time from the Ohio 36 Supercomputer Center. 
[1] Boskey AL. Biomineralization: An Overview. Connect Tissue Res 2003;44:5-9. doi:10.1080/03008200390152007.

[2] Neues F, Epple M. X-ray Microcomputer Tomography for the Study of Biomineralized Endo- and Exoskeletons of Animals. Chem Rev 2008;108:4734-41. doi:10.1021/cr078250m.

[3] Posner AS. Crystal chemistry of bone mineral. Physiol Rev 1969;49:760.

[4] Brown WE, Chow LC. Chemical properties of bone mineral. Annu Rev Mater Sci 1976;6:213-36.

[5] Kaplan FS, Hayes WC, Keaveny TM, Boskey A, Einhorn TA, Iannotti JP. Form and Function of Bone. In: Simon SR, editor. Orthop. Basic Sci. Ed. Sheldon R Simon, American Academy of Orthopaedic Surgeons; 1994.

[6] Arsenault AL. A comparative electron microscopic study of apatite crystals in collagen fibrils of rat bone, dentin and calcified turkey leg tendons. Bone Miner 1989;6:16577. doi:10.1016/0169-6009(89)90048-2.

[7] Akkus O, Adar F, Schaffler MB. Age-related changes in physicochemical properties of mineral crystals are related to impaired mechanical function of cortical bone. Bone 2004;34:443-53. doi:10.1016/j.bone.2003.11.003.

[8] Mahamid J, Aichmayer B, Shimoni E, Ziblat R, Li C, Siegel S, et al. Mapping amorphous calcium phosphate transformation into crystalline mineral from the cell to the bone in zebrafish fin rays. Proc Natl Acad Sci 2010;107:6316-21. doi:10.1073/pnas.0914218107.

[9] Müller WEG, Schröder HC, Schlossmacher U, Grebenjuk VA, Ushijima H, Wang X. Induction of carbonic anhydrase in SaOS-2 cells, exposed to bicarbonate and consequences for calcium phosphate crystal formation. Biomaterials 2013;34:8671-80. doi:10.1016/j.biomaterials.2013.07.096. [10] Phillips C, Bradley D, Schlotzhauer C, Bergfeld M, Libreros-Minotta C, Gawenis L, et al. Oim mice exhibit altered femur and incisor mineral composition and decreased bone mineral density. Bone 2000;27:219-26.

[11] Camacho NP, Hou L, Toledano TR, Ilg WA, Brayton CF, Raggio CL, et al. The material basis for reduced mechanical properties in oim mice bones. J Bone Miner Res 1999; 14:264-72.

[12] Jantou-Morris V, Horton MA, McComb DW. The nano-morphological relationships between apatite crystals and collagen fibrils in ivory dentine. Biomaterials 2010;31:5275-86. doi:10.1016/j.biomaterials.2010.03.025.

[13] Tai K, Dao M, Suresh S, Palazoglu A, Ortiz C. Nanoscale heterogeneity promotes energy dissipation in bone. Nat Mater 2007;6:454-62. doi:10.1038/nmat1911.

[14] Shackelford JF. Bioceramics: Applications of Ceramic and Glass Materials in Medicine (Materials Science Forum). 1999.

[15] Vallet-Regí M. Ceramics for medical applications. J Chem Soc Dalton Trans 2001:97-108. doi:10.1039/b007852m.

[16] Dorozhkin SV, Epple M. Biological and medical significance of calcium phosphates. Angew Chem Int Ed 2002;41:3130-46.

[17] Thamaraiselvi TV, Rajeswari S. Biological evaluation of bioceramic materials-a review. Carbon 2004;24:172.

[18] Fathi MH, Hanifi A, Mortazavi V. Preparation and bioactivity evaluation of bone-like hydroxyapatite nanopowder. J Mater Process Technol 2008;202:536-42.

doi:10.1016/j.jmatprotec.2007.10.004.

[19] Hossein Fathi M, Mortazavi V, Roohani Esfahani SI. Bioactivity Evaluation of 
Synthetic Nanocrystalline Hydroxyapatite. Dent Res J 2009;5.

[20] Kapoor S, Batra U. Preparation and Bioactivity Evaluation of Bone like Hydroxyapatite-Bioglass Composite. Int J Chem Biol Eng 2010;3:24-8.

[21] Porter AE, Patel N, Skepper JN, Best SM, Bonfield W. Comparison of in vivo dissolution processes in hydroxyapatite and silicon-substituted hydroxyapatite bioceramics. Biomaterials 2003;24:4609-20.

[22] Porter AE, Patel N, Skepper JN, Best SM, Bonfield W. Effect of sintered silicatesubstituted hydroxyapatite on remodelling processes at the bone-implant interface.

Biomaterials 2004;25:3303-14.

10 [23] Ritchie RO, Buehler MJ, Hansama P. Plasticity and toughness in bone. Phys Today $112009 ; 62: 41$. doi:10.1063/1.3156332.

12 [24] Nudelman F, Lausch AJ, Sommerdijk NAJM, Sone ED. In vitro models of collagen biomineralization. J Struct Biol 2013. doi:10.1016/j.jsb.2013.04.003.

[25] Benzerara K, Yoon TH, Tyliszczak T, Constantz B, Spormann AM, Brown GE. Scanning transmission X-ray microscopy study of microbial calcification. Geobiology 2004;2:249-59.

[26] Eichert D, Salomé M, Banu M, Susini J, Rey C. Preliminary characterization of calcium chemical environment in apatitic and non-apatitic calcium phosphates of biological interest by X-ray absorption spectroscopy. Spectrochim Acta Part B At Spectrosc 2005;60:850-8. doi:10.1016/j.sab.2005.05.012.

[27] Metzler R, Abrecht M, Olabisi R, Ariosa D, Johnson C, Frazer B, et al. Architecture of Columnar Nacre, and Implications for Its Formation Mechanism. Phys Rev Lett 2007;98. doi:10.1103/PhysRevLett.98.268102.

[28] Zhou D, Metzler RA, Tyliszczak T, Guo J, Abrecht M, Coppersmith SN, et al. Assignment of Polarization-Dependent Peaks in Carbon K-Edge Spectra from Biogenic and Geologic Aragonite. J Phys Chem B 2008;112:13128-35. doi:10.1021/jp803176z.

[29] Fleet ME, Liu X. Calcium L2,3-edge XANES of carbonates, carbonate apatite, and oldhamite (CaS). Am Mineral 2009;94:1235-41. doi:10.2138/am.2009.3228.

[30] Brandes JA, Wirick S, Jacobsen C. Carbon K-edge spectra of carbonate minerals. J Synchrotron Radiat 2010;17:676-82. doi:10.1107/S0909049510020029.

[31] Chao W, Harteneck BD, Liddle JA, Anderson EH, Attwood DT. Soft X-ray microscopy at a spatial resolution better than $15 \mathrm{~nm}$. Nature 2005;435:1210-3. doi:10.1038/nature03719.

[32] Hitchcock AP, Dynes JJ, Johansson G, Wang J, Botton G. Comparison of NEXAFS microscopy and TEM-EELS for studies of soft matter. Micron 2008;39:311-9.

doi:10.1016/j.micron.2007.09.008.

[33] Gonzalez-Jimenez ID, Cats K, Davidian T, Ruitenbeek M, Meirer F, Liu Y, et al. Hard X-ray Nanotomography of Catalytic Solids at Work. Angew Chem Int Ed 2012;51:11986-90. doi:10.1002/anie.201204930.

[34] Rubin MA, Jasiuk I, Taylor J, Rubin J, Ganey T, Apkarian RP. TEM analysis of the nanostructure of normal and osteoporotic human trabecular bone. Bone 2003;33:270-82.

[35] Fratzl P, Gupta HS, Paschalis EP, Roschger P. Structure and mechanical quality of the collagen-mineral nano-composite in bone. J Mater Chem 2004;14:2115.

doi:10.1039/b402005g.

[36] Wirth R. Water in minerals detectable by electron energy-loss spectroscopy EELS. Phys Chem Miner 1997;24:561-8.

[37] Heimann R, Wirth R. Formation and transformation of amorphous calcium phosphates on titanium alloy surfaces during atmospheric plasma spraying and their subsequent in vitro performance. Biomaterials 2006;27:823-31.

doi:10.1016/j.biomaterials.2005.06.029. 
[38] Garvie LAJ. Can electron energy-loss spectroscopy (EELS) be used to quantify hydrogen in minerals from the O K edge? Am Mineral 2009;95:92-7.

doi:10.2138/am.2010.3290.

[39] Jarcho M, Bolen CH, Thomas MB, Bobick J, Kay JF, Doremus RH. Hydroxylapatite synthesis and characterization in dense polycrystalline form. J Mater Sci 1976;11:2027-35.

[40] Akao M, Aoki H, Kato K. Mechanical properties of sintered hydroxyapatite for prosthetic applications. J Mater Sci 1981;16:809-12.

[41] Gibson IR, Bonfield W. Novel synthesis and characterization of an AB-type carbonate-substituted hydroxyapatite. J Biomed Mater Res 2002;59:697-708.

doi:10.1002/jbm.10044.

[42] Klein CPAT, De Groot K, Driessen AA, Van der Lubbe HBM. A comparative study of different $\beta$-whitlockite ceramics in rabbit cortical bone with regard to their biodegradation behaviour. Biomaterials 1986;7:144-6.

[43] Kłosowski MM, Shefelbine SJ, Porter AE, McComb DW. Analytical Electron Microscopy of Bone and Mineralized Tissue. Handb. Imaging Biol. Mech., CRC Press; 2014, p. 491-506.

[44] Vignoles M, Bonel G, Holcomb DW, Young RA. Influence of preparation conditions on the composition of type B carbonated hydroxyapatite and on the localization of the carbonate ions. Calcif Tissue Int 1988;43:33-40. doi:10.1007/BF02555165.

[45] Rey C, Collins B, Goehl T, Dickson IR, Glimcher MJ. The carbonate environment in bone mineral: a resolution-enhanced Fourier transform infrared spectroscopy study. Calcif Tissue Int 1989;45:157-64.

[46] Fleet ME, Liu X. Coupled substitution of type A and B carbonate in sodium-bearing apatite. Biomaterials 2007;28:916-26. doi:10.1016/j.biomaterials.2006.11.003.

[47] Boonrungsiman S, Gentleman E, Carzaniga R, Evans ND, McComb DW, Porter AE, et al. The role of intracellular calcium phosphate in osteoblast-mediated bone apatite formation. Proc Natl Acad Sci 2012;109:14170-5. doi:10.1073/pnas.1208916109.

[48] De la Peña F, Berger M-H, Hochepied J-F, Dynys F, Stephan O, Walls M. Mapping titanium and tin oxide phases using EELS: An application of independent component analysis. Ultramicroscopy 2011;111:169-76. doi:10.1016/j.ultramic.2010.10.001.

[49] Hyperspy: Hyperspectral data analysis toolbox. 2013.

[50] Hyvärinen A, Oja E. Independent component analysis: algorithms and applications. Neural Netw 2000;13:411-30.

[51] Kresse G, Hafner J. Ab initio molecular dynamics for liquid metals. Phys Rev B $1993 ; 47$.

[52] Kresse G, Hafner J. Ab initio molecular-dynamics simulation of the liquid-metalamorphous-semiconductor transition in germanium. Phys Rev B 1994;49:14251.

[53] Kresse G, Furthmüller J. Efficiency of ab-initio total energy calculations for metals and semiconductors using a plane-wave basis set. Comput Mat Sci 1996;6.

[54] Kresse G, Furthmüller J. Efficient iterative schemes for ab initio total-energy calculations using a plane-wave basis set. Phys Rev B 1996;54:11169.

[55] Blöchl PE. Projector augmented-wave method. Phys Rev B 1994;50:17953.

[56] Kresse G, Joubert D. From ultrasoft pseudopotentials to the projector augmentedwave method. Phys Rev B 1999;59:1758.

[57] Perdew JP, Burke K, Ernzerhof M. Generalized gradient approximation made simple. Phys Rev Lett 1996;77:3865.

[58] Perdew JP, Burke K, Ernzerhof M. Erratum: Generalized gradient approximation made simple. Phys Rev Lett 1997;78:1396.

[59] Buczko R, Duscher G, Pennycook SJ, Pantelides ST. Excitonic effects in coreexcitation spectra of semiconductors. Phys Rev Lett 2000;85:2168. 
[60] Kruse J, Leinweber P, Eckhardt K-U, Godlinski F, Hu Y, Zuin L. Phosphorus L2,3 edge XANES: overview of reference compounds. J Synchrotron Radiat 2009;16:247-59. doi:10.1107/S0909049509000211.

[61] Hansen PL, Brydson R, McComb DW. $p \rightarrow$ p-like transitions at the silicon L2,3edges of silicates. Microsc Microanal Microstruct 1992;3:213-9.

doi:10.1051/mmm:0199200302-3021300.

[62] McComb DW, Brydson R, Hansen PL, Payne RS. Qualitative interpretation of electron energy-loss near-edge structure in natural zircon. J Phys Condens Matter 1992;4:8363.

10 [63] Sutherland DGJ, Kasrai M, Bancroft GM, Liu ZF, Tan KH. Si L-and K-edge X-rayabsorption near-edge spectroscopy of gas-phase $\mathrm{Si}(\mathrm{CH} 3) \mathrm{x}(\mathrm{OCH} 3)$ 4-x: Models for solidstate analogs. Phys Rev B 1993;48:14989.

[64] Srot V, Wegst UGK, Salzberger U, Koch CT, Hahn K, Kopold P, et al. Microstructure, chemistry, and electronic structure of natural hybrid composites in abalone shell. Micron 2013;48:54-64. doi:10.1016/j.micron.2013.02.010.

[65] Benzerara K, Menguy N, López-García P, Yoon T-H, Kazmierczak J, Tyliszczak T, et al. Nanoscale detection of organic signatures in carbonate microbialites. Proc Natl Acad Sci 2006;103:9440-5.

[66] Benzerara K, Tyliszczak T, Brown Jr GE. Study of Interactions Between Microbes and Minerals by Scanning Transmission X-Ray Microscopy (STXM). AIP Conf. Proc., vol. 882, 2007, p. 726.

[67] Cody GD, Ade H, Wirick S, Mitchell GD, Davis A. Determination of chemicalstructural changes in vitrinite accompanying luminescence alteration using C-NEXAFS analysis. Org Geochem 1998;28:441-55.

[68] Braun A, Kubatova A, Wirick S, Mun SB. Radiation damage from EELS and NEXAFS in diesel soot and diesel soot extracts. J Electron Spectrosc Relat Phenom 2009;170:42-8. doi:10.1016/j.elspec.2007.08.002.

[69] Lam RSK, Metzler RA, Gilbert PUPA, Beniash E. Anisotropy of Chemical Bonds in Collagen Molecules Studied by X-ray Absorption Near-Edge Structure (XANES) Spectroscopy. ACS Chem Biol 2012;7:476-80. doi:10.1021/cb200260d.

[70] Metzler RA, Kim IW, Delak K, Evans JS, Zhou D, Beniash E, et al. Probing the Organic-Mineral Interface at the Molecular Level in Model Biominerals. Langmuir 2008;24:2680-7. doi:10.1021/la7031237.

[71] Garvie LAJ, Craven AJ, Brydson R. Use of electron-energy loss near-edge fine structure in the study of minerals. Am Mineral 1994;79:411-25.

[72] Leapman RD, Grunes LA, Fejes PL. Study of the L_ 2,3 edges in the 3d transition metals and their oxides by electron-energy-loss spectroscopy with comparisons to theory. Phys Rev B 1982;26:614.

[73] Van der Laan G, Kirkman IW. The 2p absorption spectra of 3d transition metal compounds in tetrahedral and octahedral symmetry. J Phys Condens Matter 1992;4:4189.

[74] Egerton RF. Electron Energy-Loss Spectroscopy in the Electron Microscope. 2nd ed. 1996.

[75] Beniash E, Metzler RA, Lam RSK, Gilbert PUPA. Transient amorphous calcium phosphate in forming enamel. J Struct Biol 2009;166:133-43. doi:10.1016/j.jsb.2009.02.001. [76] Mkhoyan KA, Silcox J, Mcguire MA, Disalvo FJ. Radiolytic purification of CaO by electron beams. Philos Mag 2006;86:2907-17. doi:10.1080/14786430600658025.

[77] Aronova MA, Sousa AA, Leapman RD. EELS characterization of radiolytic products in frozen samples. Micron 2011;42:252-6. doi:10.1016/j.micron.2010.10.009.

[78] Bres EF, Hutchison JL, Senger B, Voegel J-C, Frank RM. HREM study of irradiation damage in human dental enamel crystals. Ultramicrotomy 1991;35:305-22. 
doi:http://dx.doi.org/10.1016/0304-3991(91)90083-I.

[79] Eddisford P, Brown A, Brydson R. Identifying and quantifying the mechanism of electron beam induced damage and recovery in hydroxyapatite. J Phys Conf Ser 2008;126. doi:10.1088/1742-6596/126/1/012008.

[80] Brès EF, Michel J, Reyes-Gasga J, Mussi A, Rey C. Damage in apatite during TEM observation. Acta Microsc., vol. 20, Mérida Yucatán, México: 2011.

[81] Metzler R, Zhou D, Abrecht M, Chiou J-W, Guo J, Ariosa D, et al. Polarizationdependent imaging contrast in abalone shells. Phys Rev B 2008;77.

doi:10.1103/PhysRevB.77.064110.

[82] Grunes LA, Leapman RD, Wilker CN, Hoffmann R, Kunz AB. Oxygen K near-edge fine structure: An electron-energy-loss investigation with comparisons to new theory for selected 3d transition-metal oxides. Phys Rev B 1982;25:7157.

[83] De Groot FMF, Grioni M, Fuggle JC, Ghijsen J, Sawatzky A, Petersen H. Oxygen 1s X-ray-absorption edges of transition-metal oxides. Phys Rev B 1989;40.

[84] Gregori G, Kleebe H-J, Mayr H, Ziegler G. EELS characterisation of $\beta$-tricalcium phosphate and hydroxyapatite. J Eur Ceram Soc 2006;26:1473-9.

doi:10.1016/j.jeurceramsoc.2005.02.007.

[85] Ardanova LI, Get'man EI, Loboda SN, Prisedsky VV, Tkachenko TV, Marchenko VI, et al. Isomorphous Substitutions of Rare Earth Elements for Calcium in Synthetic

Hydroxyapatites. Inorg Chem 2010;49:10687-93. doi:10.1021/ic1015127.

[86] SQS. n.d.

[87] Brydson R, Bruley J, Thomas JM. Further evidence for core-hole effects in the nearedge structures of light-element K-edges. Chem Phys Lett 1988;149:343-7.

[88] Wilson RM, Elliott JC, Dowker SE., Smith RI. Rietveld structure refinement of precipitated carbonate apatite using neutron diffraction data. Biomaterials 2004;25:2205-13. doi:10.1016/j.biomaterials.2003.08.057.

[89] Srot V, Bussmann B, Salzberger U, Koch CT, van Aken PA. Linking Microstructure and Nanochemistry in Human Dental Tissues. Microsc Microanal 2012;18:509-23. doi:10.1017/S1431927612000116.

[90] Jantou V, Turmaine M, West GD, Horton MA, McComb DW. Focused ion beam milling and ultramicrotomy of mineralised ivory dentine for analytical transmission electron microscopy. Micron 2009;40:495-501. doi:10.1016/j.micron.2008.12.002.

[91] Gupta HS, Seto J, Wagermaier W, Zaslansky P, Boesecke P, Fratzl P. Cooperative deformation of mineral and collagen in bone at the nanoscale. Proc Natl Acad Sci 2006;103:17741-6. doi:10.1073/pnas.0604237103.

[92] Fratzl P, Wagermaier W, Gourrier A, Kerschnitzki M, Burghammer M, Seidel R, et al. Synchrotron 3D SAXS analysis of bone nanostructure. Bioinspired Biomim

Nanobiomaterials 2012;1:123-31. doi:10.1680/bbn.11.00014.

[93] Amarie S, Zaslansky P, Kajihara Y, Griesshaber E, Schmahl WW, Keilmann F. NanoFTIR chemical mapping of minerals in biological materials. Beilstein J Nanotechnol 2012;3:312-23. doi:10.3762/bjnano.3.35. 


\begin{tabular}{|l|c|l|}
\hline Mineral name and formula & Abbreviation & Notes \\
\hline $\begin{array}{l}\text { Hydroxyapatite } \\
\mathrm{Ca}_{10}\left(\mathrm{PO}_{4}\right)_{6}(\mathrm{OH})_{2}\end{array}$ & $\mathrm{HA}$ & As precipitated and heated to $1200^{\circ} \mathrm{C}$ \\
\hline $\begin{array}{l}\text { Carbonated hydroxyapatite } \\
\mathrm{Ca}_{10}\left(\mathrm{PO}_{4}\right)_{6-\mathrm{x}}\left(\mathrm{CO}_{3}\right)_{\mathrm{x}}(\mathrm{OH})_{2-\mathrm{y}}\left(\mathrm{CO}_{3}\right)_{\mathrm{y}}\end{array}$ & $\mathrm{CHA}$ & $\begin{array}{l}\mathrm{Ca} / \mathrm{P}=1.76, \text { heated to } 800^{\circ} \mathrm{C}, \mathrm{A} / \mathrm{B}=0.099 \\
\mathrm{Ca} / \mathrm{P}=1.74, \text { heated to } 900^{\circ} \mathrm{C}, \mathrm{A} / \mathrm{B}=0.168\end{array}$ \\
\hline $\begin{array}{l}\beta \text {-tricalcium phosphate } \\
\mathrm{Ca}_{3}\left(\mathrm{PO}_{4}\right)_{2}\end{array}$ & bTCP & Heated to $1100^{\circ} \mathrm{C}$ \\
\hline $\begin{array}{l}\mathrm{Calcium}_{\text {carbonate }} \text { calcite } \\
\mathrm{CaCO}_{3}\end{array}$ & $\mathrm{CAL}$ & $\begin{array}{l}\text { Sigma Aldrich } 239216, \text { ACS Reagent }>= \\
99.0 \%,\end{array}$ \\
\hline
\end{tabular}

3

Table 1. List of standards used in the EELS study

4

\begin{tabular}{|c|c|l|}
\hline Ca/P ratio & Temperature $^{\circ} \mathbf{C}$ & A/B ratio \\
\hline 1.76 & 800 & 0.99 \\
\hline 1.76 & 900 & 1.02 \\
\hline 1.74 & 900 & 1.27 \\
\hline 1.76 & 1000 & 1.46 \\
\hline 1.72 & 900 & 1.54 \\
\hline 1.72 & 800 & 1.63 \\
\hline 1.74 & 800 & 1.68 \\
\hline
\end{tabular}

5

Table 2. $\mathrm{A} / \mathrm{B}$ ratios in ascending order for $\mathrm{CHA}$ produced using various $\mathrm{Ca} / \mathrm{P}$ and heat treatment temperatures. The two extreme $\mathrm{A} / \mathrm{B}$ ratios were used in the TEM-EELS study. 


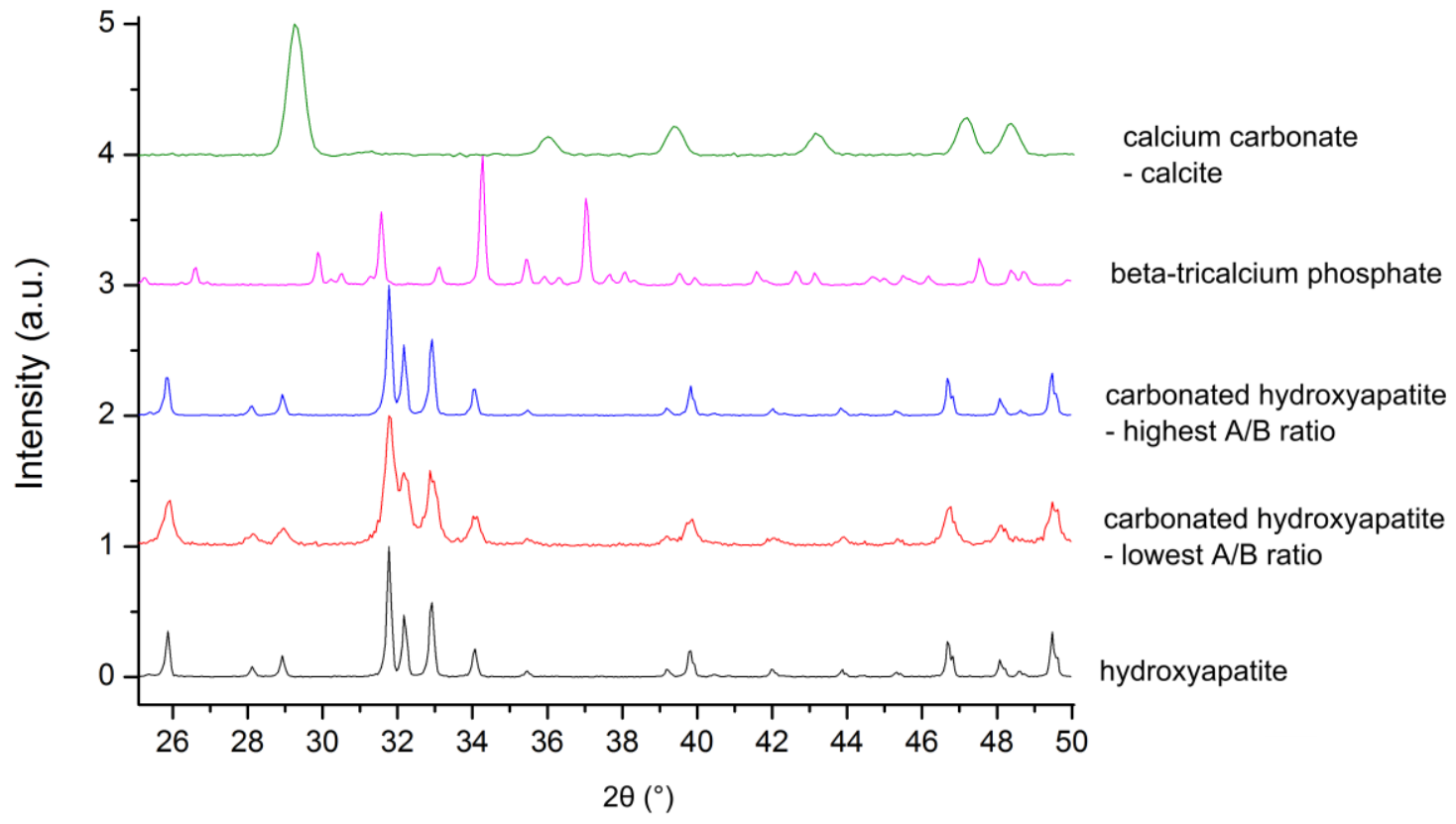

1

2 Figure 1. Representative XRD patterns of selected mineral standards used in STEM-EELS studies. The lower 3 crystallinity shown in carbonated HA (lowest $\mathrm{A} / \mathrm{B}$ ratio) is due to the lower heat treatment temperature and lower $4 \mathrm{Ca} / \mathbf{P}$ ratio. 


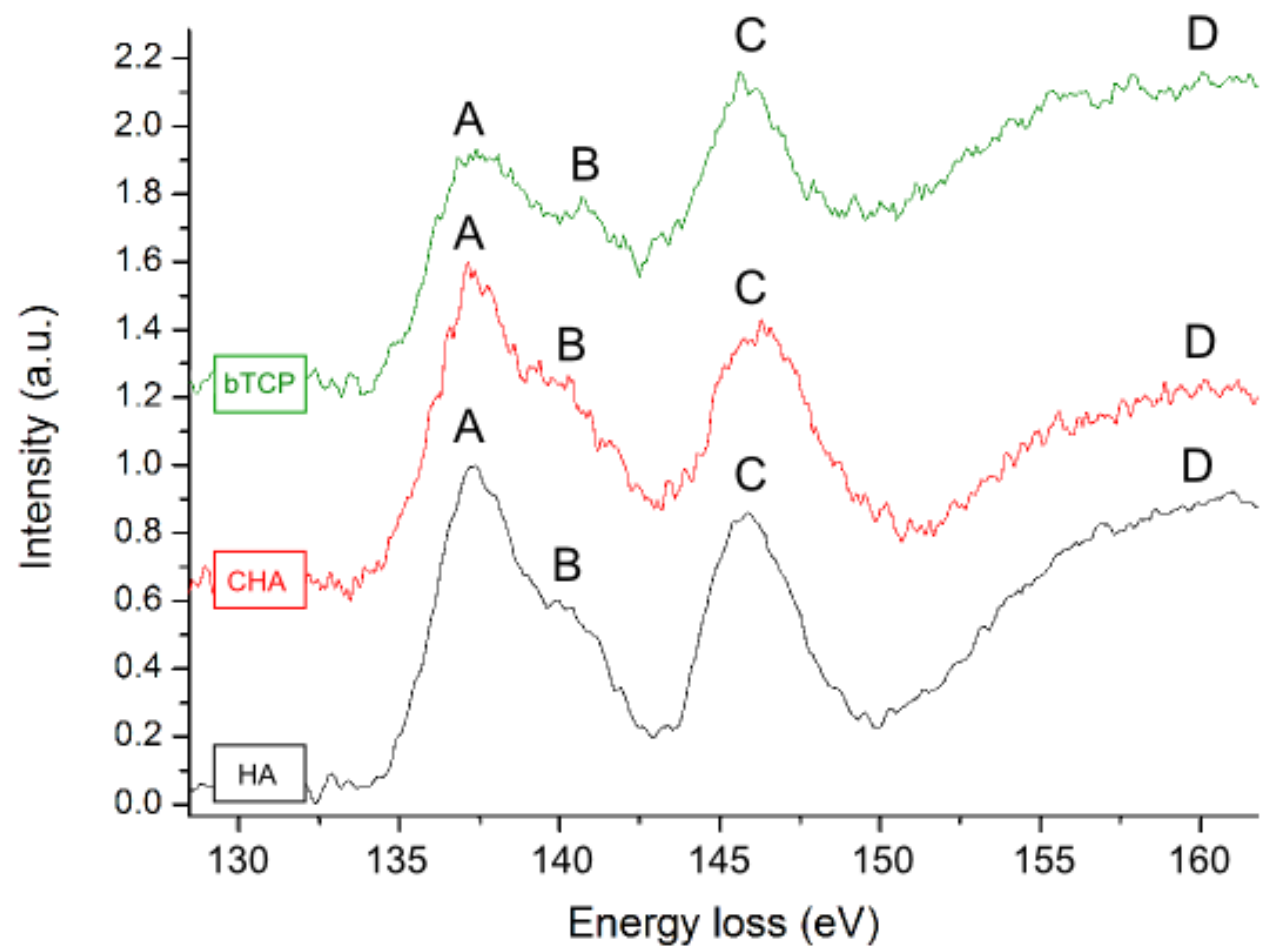

1

2 Figure 2. Phosphorus $\mathrm{L}_{2,3}$-edge structures of hydroxyapatite (HA), carbonated hydroxyapatite (CHA) and betatricalcium phosphate (bTCP). All phosphate-containing minerals displayed a characteristic pattern of two main peaks: peak $A$ and peak $C$ followed by a broad peak $D$. 


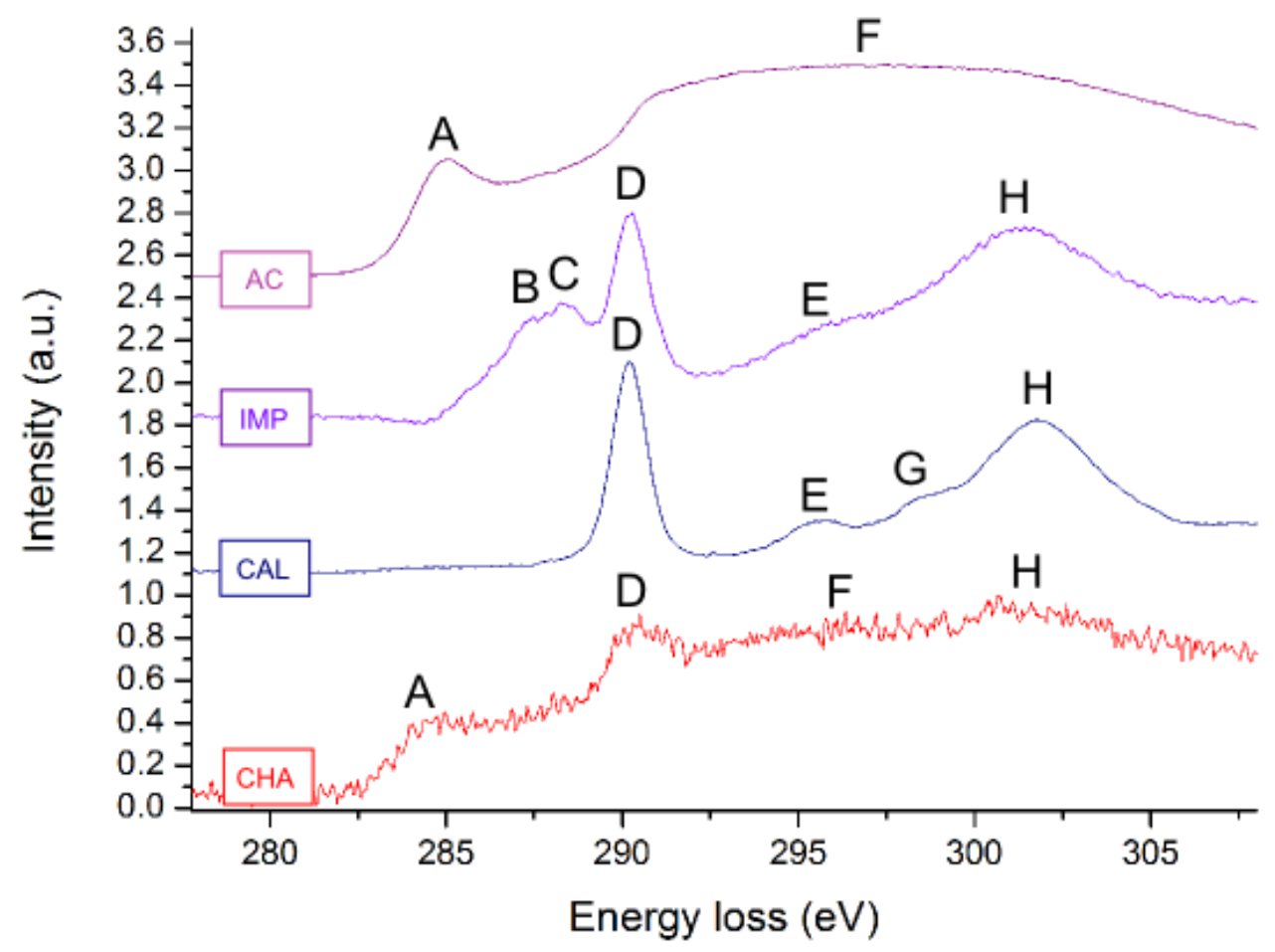

1

2 Figure 3. Carbon K-edge structures of carbonated hydroxyapatite (CHA), calcite (CAL), an impurity (IMP) in the sample, and amorphous carbon (AC). The carbonate-containing minerals (CHA, CAL, IMP) display a sharp peak D at $290 \mathrm{eV}$ and a less intense peak $\mathrm{H}$ at $302 \mathrm{eV}$. The IMP edge was obtained via independent component analysis (ICA; Figure 4). 


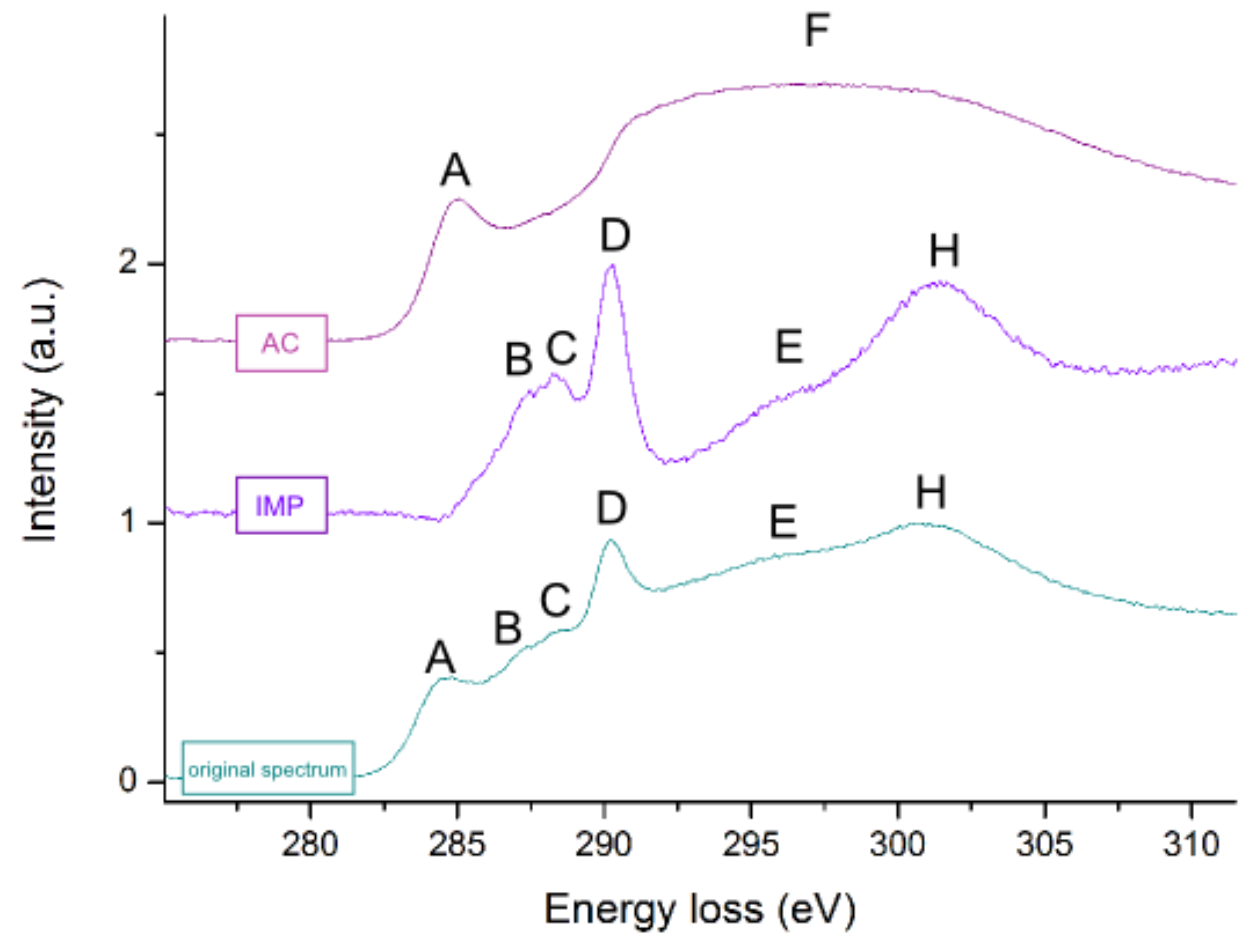

1

2 Figure 4. The original carbon K-edge spectrum acquired from an impurity crystal grain found within the calcite sample. The amorphous carbon film (AC) and impurity (IMP) spectra were reconstructed by the ICA method.

4 


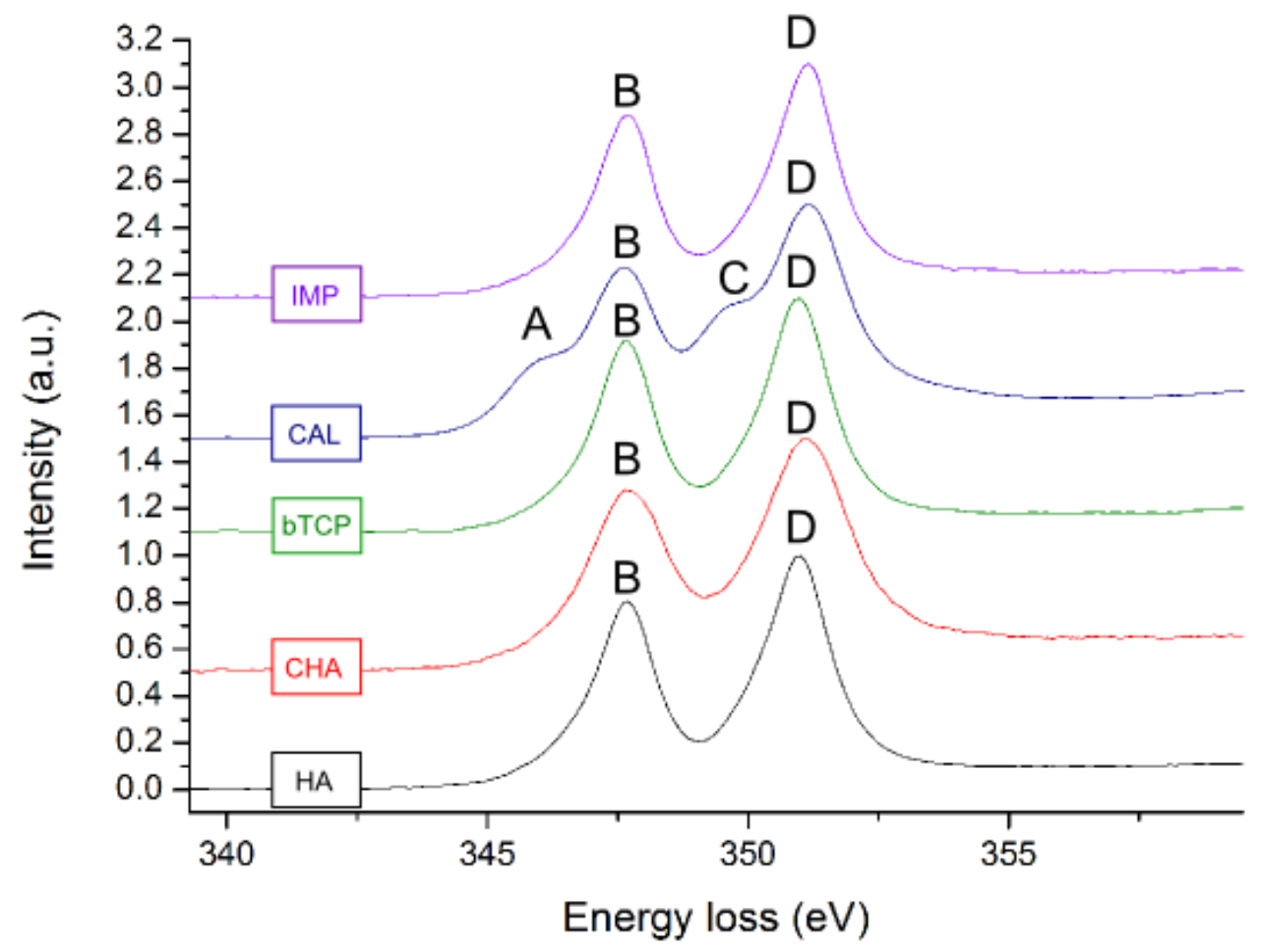

1

Figure 5. Calcium $\mathrm{L}_{2,3}$-edge structures of hydroxyapatite (HA), carbonated hydroxyapatite (CHA), beta-tricalcium phosphate (bTCP), calcite (CAL) and the impurity (IMP) in the calcite sample. All specimens displayed two peaks B and D characteristic of the calcium L-edge. All minerals containing carbonate groups showed a small shift of peak D towards higher energies, in comparison to the pure calcium phosphates (HA, bTCP). Only CAL displayed additional peaks $A$ and $C$ characteristic of multiplet splitting. 


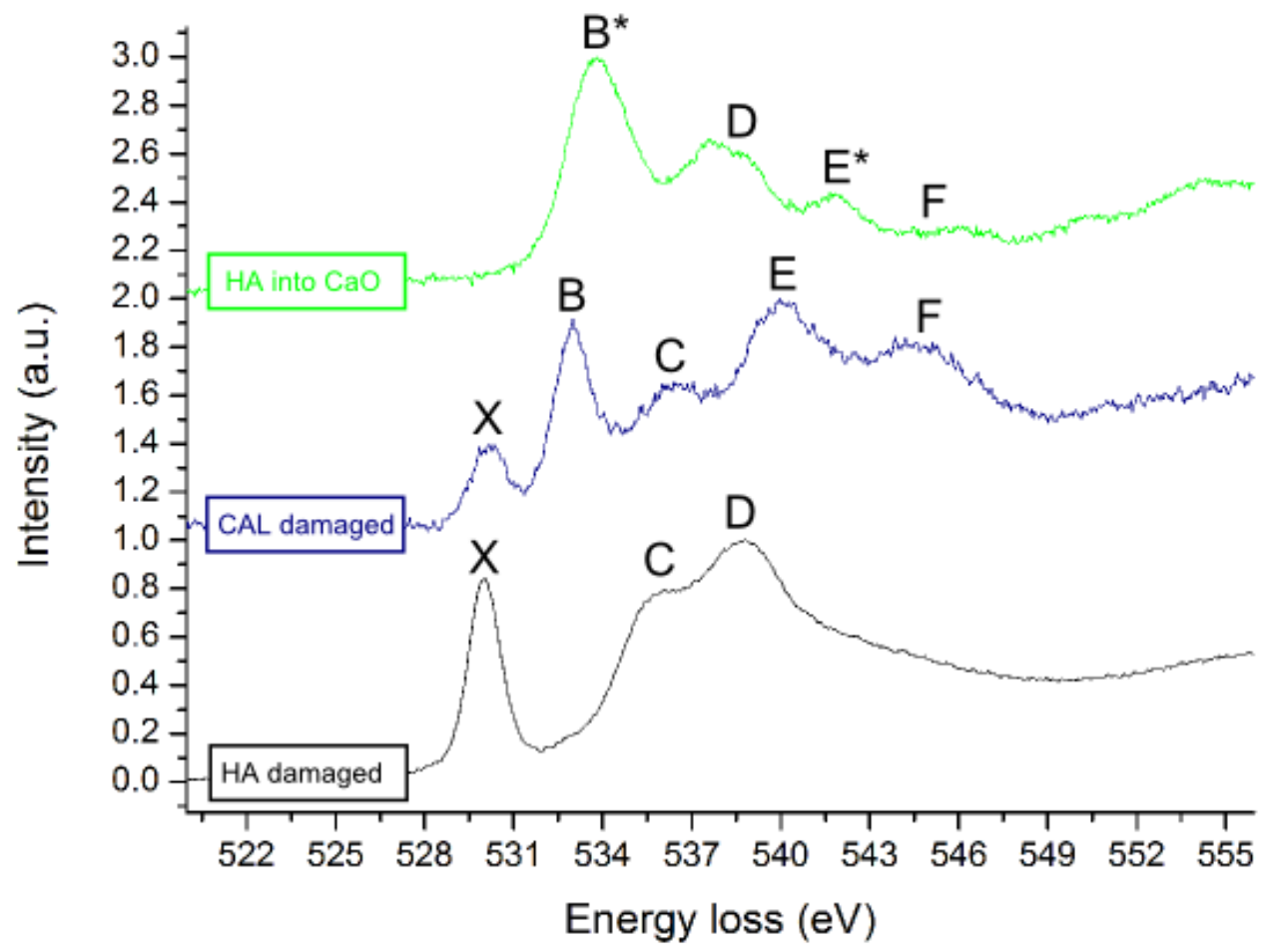

1

2 Figure 6. Damage markers seen in the oxygen K-edge. CAL (calcite) and HA (hydroxyapatite) display an additional peak at $530 \mathrm{eV}$ when exposed to an electron dose above $10^{4}$ electrons $/ \mathrm{nm}^{2}$. The spectrum obtained from $\mathrm{HA}$ exposed to an electron dose above $10^{5}$ electrons $/ \mathrm{nm}^{2}$ ( $\mathrm{HA}$ into $\left.\mathrm{CaO}\right)$ is consistent with calcium oxide spectra presented in the literature. $\mathrm{CaO}$ exhibits additional peaks marked as $\mathrm{B}^{*}$ and $\mathrm{E}^{*}$. 


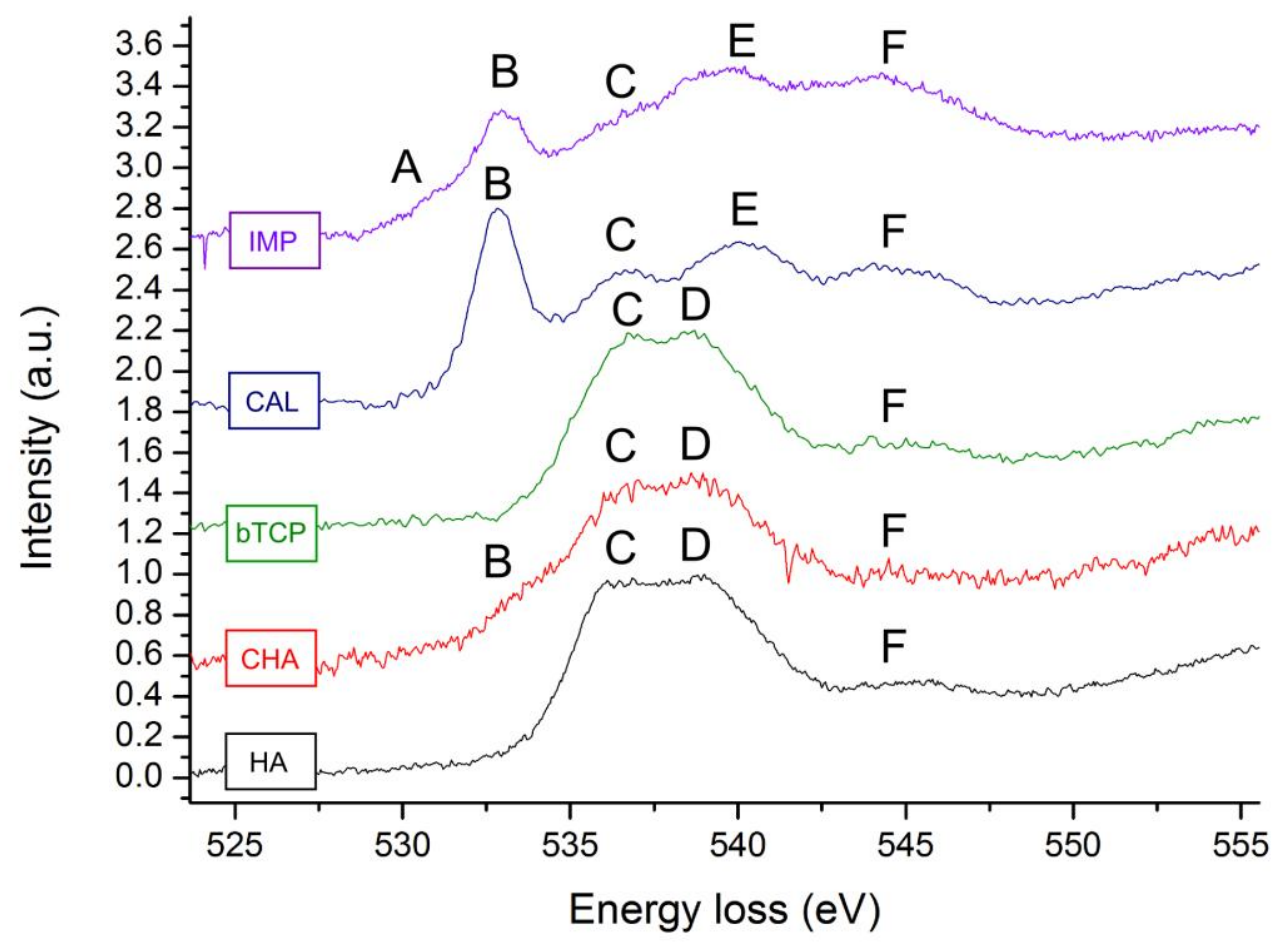

Figure 7. Oxygen K-edge structures of hydroxyapatite (HA), carbonated hydroxyapatite (CHA), beta-tricalcium phosphate (bTCP), calcite (CAL) and the aragonite-like impurity (IMP). Calcium carbonates (CAL, IMP) display a characteristic peak B. Calcium phosphates (HA, CHA, bTCP) display a characteristic double peak C-D. 
Hydroxyapatite Oxygen K edge

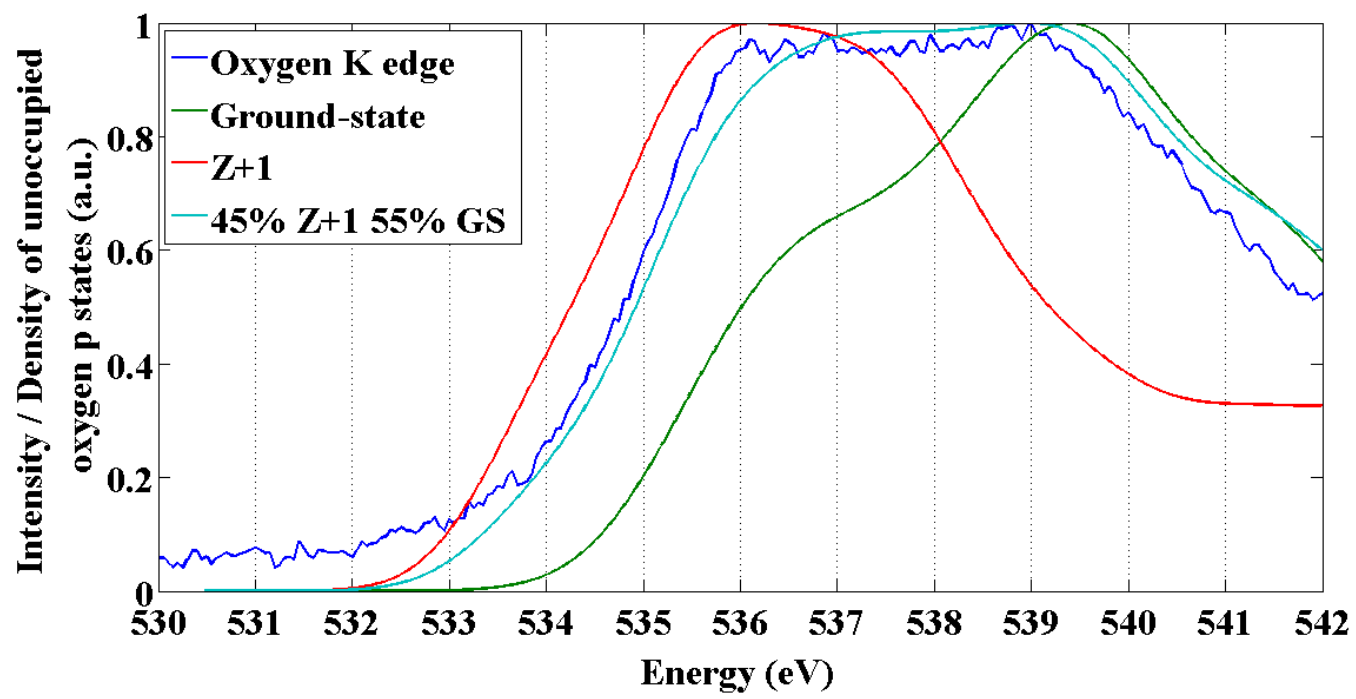

3 Figure 8. EELS spectra plotted along with the unoccupied site projected density of «p» states of all oxygen atoms present in hydroxyapatite structure. The blue curve is a ground state calculation while the green curve represents an excited state approximation obtained through the use of a $\mathrm{Z}+1$ approximation. The light blue curve is a linear combination of both the ground-state and $\mathrm{Z}+1$ calculation. 
Type AB CHA

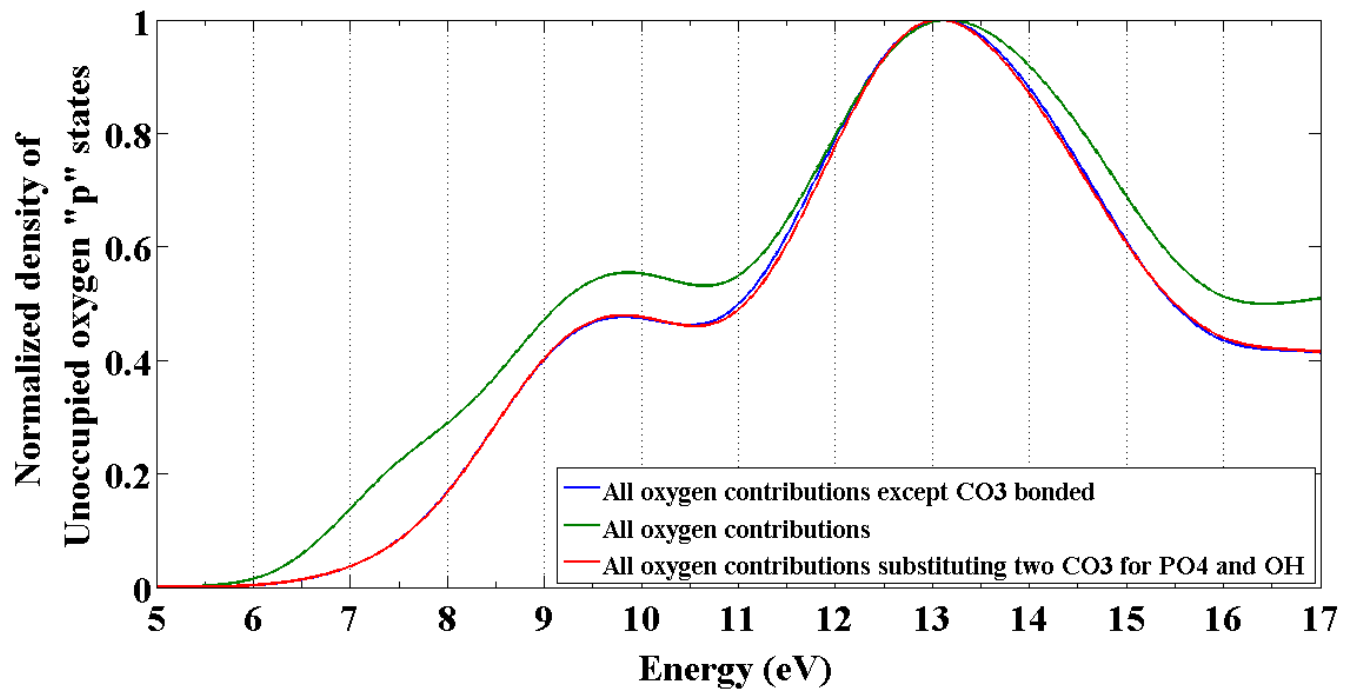

Figure 9. The ground-state unoccupied density of oxygen «p» states for type AB carbonated hydroxyapatite. The green curve includes contributions from all oxygen atoms while the blue curve shows the contributions from all oxygen atoms except those involved in a carbonate group. The red curve represents contributions from all oxygen atoms except carbonated bonded oxygen atoms, and in lieu of these carbonate bonded oxygen atoms contributions from the ions that were substituted for carbonates are included. The red curve effectively models non-substituted hydroxyapatite. All plots are normalized. 

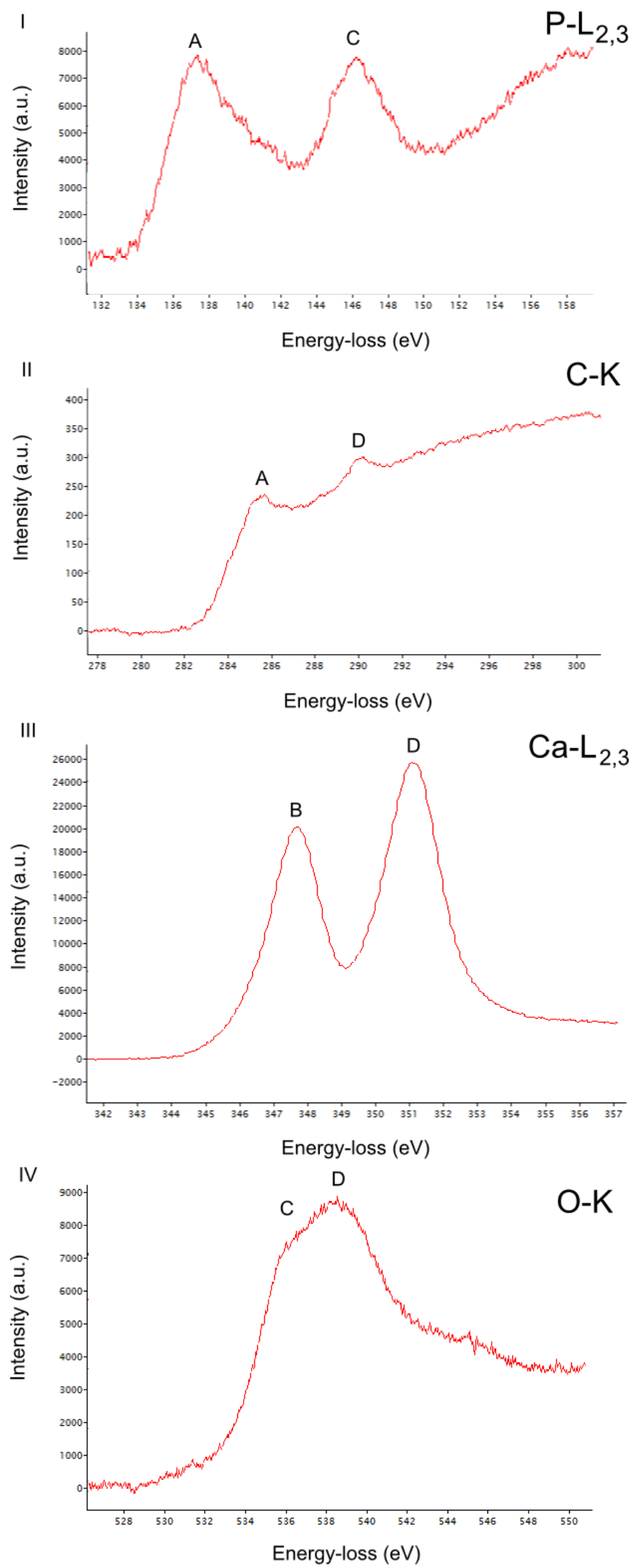

2 Figure 10. Representative EELS spectra of phosphorus (I), carbon (II), calcium (III) and oxygen (IV) edges collected from wild type mouse bone. The major peaks in each of the edges were labelled as in Figure 2, Figure 3, Figure 5 and Figure 7. 


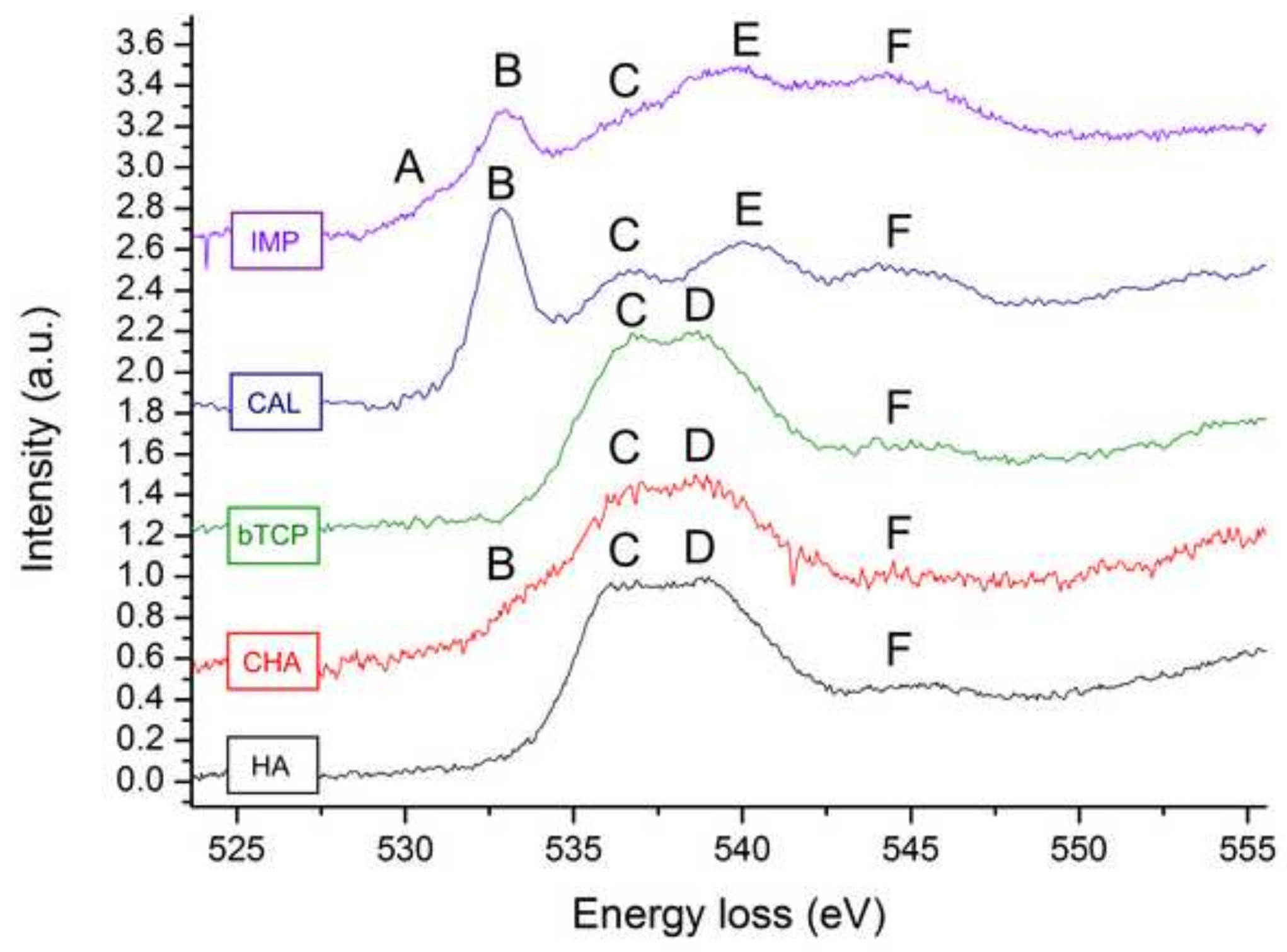

